\title{
Potential Vorticity Mixing and Rapid Intensification in the Numerically Simulated Supertyphoon Haiyan (2013) $\mathcal{O}$
}

\author{
SATOKI TSUJINO ${ }^{\mathrm{a}}$ AND HUNG-CHI KUO \\ Department of Atmospheric Sciences, National Taiwan University, Taipei, Taiwan
}

(Manuscript received 19 August 2019, in final form 25 March 2020)

\begin{abstract}
The inner-core dynamics of Supertyphoon Haiyan (2013) undergoing rapid intensification (RI) are studied with a 2-km-resolution cloud-resolving model simulation. The potential vorticity (PV) field in the simulated storm reveals an elliptical and polygonal-shaped eyewall at the low and middle levels during RI onset. The PV budget analysis confirms the importance of PV mixing at this stage, that is, the asymmetric transport of diabatically generated PV to the storm center from the eyewall and the ejection of PV filaments outside the eyewall. We employ a piecewise PV inversion (PPVI) and an omega equation to interpret the model results in balanced dynamics. The omega equation diagnosis suggests eye dynamical warming is associated with the PV mixing. The PPVI indicates that PV mixing accounts for about $50 \%$ of the central pressure fall during RI onset. The decrease of central pressure enhances the boundary layer (BL) inflow. The BL inflow leads to contraction of the radius of the maximum tangential wind (RMW) and the formation of a symmetric convective PV tower inside the RMW. The eye in the later stage of the RI is warmed by the subsidence associated with the convective PV towers. The results suggest that the pressure change associated with PV mixing, the increase of the symmetric BL radial inflow, and the development of a symmetric convective PV tower are the essential collaborating dynamics for RI. An experiment with 500-m resolution shows that the convergence of BL inflow can lead to an updraft magnitude of $20 \mathrm{~m} \mathrm{~s}^{-1}$ and to a convective PV tower with a peak value of $200 \mathrm{PVU}\left(1 \mathrm{PVU}=10^{-6} \mathrm{~K} \mathrm{~kg}^{-1} \mathrm{~m}^{2} \mathrm{~s}^{-1}\right)$.
\end{abstract}

\section{Introduction}

Although the forecast skill for tropical cyclone (TC) tracks has steadily improved during the past decades, intensity forecasts have made much slower progress and remain a highly challenging problem (DeMaria et al. 2007, 2014; Rogers et al. 2013a). Significant intensity errors tend to occur for TCs that undergo rapid intensification (RI; Ito 2016), which is usually defined as a process where the maximum wind speed $V_{\max }$ increases at the 95th percentile of all TC intensity changes over water (Kaplan and DeMaria 2003), or $V_{\max }$ increases

Supplemental information related to this paper is available at the Journals Online website: https://doi.org/10.1175/JAS-D-190219.s1.

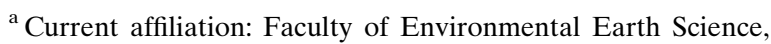
Hokkaido University, Sapporo, Japan.
}

Corresponding author: Hung-Chi Kuo, kuo@as.ntu.edu.tw greater than $19.5 \mathrm{~m} \mathrm{~s}^{-1}$ in $24 \mathrm{~h}$ in the western North Pacific (WNP; Hendricks et al. 2010).

There are many factors across a wide range of scales that affect the RI process. Kaplan and DeMaria (2003) identified synoptic conditions conducive to RI, including weak vertical wind shear, an upper-level trough, stronger upper-level easterlies, a cold-core low, high relative humidity at low levels, and warm sea surface temperatures (SSTs). Hendricks et al. (2010), however, suggest no significant difference between the intensifying group and the RI group a wide variety of environmental conditions (such as deep-layer shear, humidity, low-level vorticity and convergence, and upper-level divergence) for TCs in the WNP and in the Atlantic during 2003-08 according to the 24-h intensity changes in $V_{\text {max }}$. Namely, their results indicate that in the presence of a favorable environment for the TCs to intensify, there is no further distinction in synoptic conditions on whether a RI will occur or not. Harnos and Nesbitt (2016) and Tao and Jiang (2015) have suggested that the RI group of TCs also have a higher degree of axisymmetry in precipitation before and during RI. Moreover, airborne Doppler 
radar observations indicate that intensifying TCs have a semicomplete eyewall structure with more convection inside the radius of maximum winds (RMW) than that of the nonintensifying storms (Rogers et al. 2013b, 2016; Zawislak et al. 2016). Thus, factors such as the degree of symmetry and the deep convection in the inertially stable region inside of the RMW may be relevant for internal dynamics of RI (e.g., Schubert and Hack 1982; Smith and Montgomery 2016).

Since RI is more likely to occur in an intense TC (Shu et al. 2012), it is possible that nonlinear interaction across scales is essential in the RI process. The RI internal dynamics may be viewed with perspectives of the balanced-unbalanced and the symmetric-asymmetric dynamics. Within the framework of an axisymmetric and balanced vortex, Schubert and Hack (1982) studied the Eliassen transverse circulation equation with eyewall heating and indicated that both the vortex structure and the location of diabatic heating play crucial roles in the intensification of TCs. Vigh and Schubert (2009) found that the warm core in TCs may rapidly develop if a portion of the deep convection occurs inside the RMW. Schubert et al. (1999) studied the axisymmetrization of potential vorticity $(\mathrm{PV})$ by mixing of $\mathrm{PV}$ into the eye from the eyewall PV ring. Kossin and Schubert (2001) and Hendricks et al. (2009) showed that PV mixing leads to a decrease in the minimum sea level pressure similar to that in RI. The pressure reduction may be due to the balanced response of the asymmetric dynamics of PV mixing. The balanced response may also produce a lower-level inversion of temperature (referred to as dynamical eye warming) in the storm center associated with the PV bridge profile (Hendricks and Schubert 2010; Yau et al. 2004).

A decrease in central pressure and increase in the horizontal pressure gradient will generally lead to an increase the boundary layer (BL) radial inflow. Smith et al. (2009) suggested that the unbalanced BL inflow is generally stronger than that of the balanced symmetric Eliassen response. The large unbalanced inflow in the BL may exert a substantial control on the contraction of the RMW, the location of the eyewall updraft and organization of deep convection (Montgomery and Smith 2017; Kuo et al. 2019, hereinafter referred to as K19). Williams et al. (2013) reported shock-like structures in radial inflow with $20 \mathrm{~m} \mathrm{~s}^{-1}$ updrafts near the top of the BL in Hurricane Hugo (1989). Hausman et al. (2006) performed a full-physics axisymmetric two-dimensional simulation with a grid spacing of $500 \mathrm{~m}$ under an idealized condition. They found a narrow leaning convective tower in which the value of PV can reach several hundred potential vorticity units (PVU; 1 PVU = $10^{-6} \mathrm{~K} \mathrm{~kg}^{-1} \mathrm{~m}^{2} \mathrm{~s}^{-1}$ ) in the eyewall during the mature stage of the simulation. The high-PV values in the tower can be due to the collocation of the strong eyewall convection with large vorticity field. A convective PV tower with hundreds of PVU has been recently reported from an observational study of Hurricane Patricia (2015) during its RI period (Martinez et al. 2019).

Supertyphoon Haiyan (2013), historically the most intense TC in the WNP, experienced a period of RI in which the maximum wind speed increased by $31 \mathrm{~m} \mathrm{~s}^{-1}$ in $24 \mathrm{~h}$. K19 simulated the RI of Haiyan with a 2-kmhorizontal-resolution cloud-resolving model, and analyzed its dynamic efficiency factor (DEF), which measures the local efficiency of convective heating in generating kinetic energy of an axisymmetric vortex. In the presence of strong subsidence and baroclinicity near the eyewall, DEF is large. The simulated TC during the RI period becomes more axisymmetric, and the deep convection becomes collocated with the large DEF area near the eyewall. K19 also highlight the importance of the PV mixing and axisymmetrization dynamics (e.g., Schubert et al. 1999), the strong BL updraft that resulted from a shock-like structure in the BL radial flow, and the production of a high-PV convective tower near the eyewall in the RI processes.

The PV includes information on wind and mass fields, and evolution of the PV is in part related to the development of the balanced wind and mass fields (e.g., Hausman et al. 2006). The partition of wind and mass contribution to the PV field, however, is quite different according to the storm strength. Stronger storms are with smaller Rossby radii of deformation and larger Rossby heights (Schubert and McNoldy 2010), which means the stronger storms favor mass (pressure) response in a more vertically elongated structure. The vertical elongated pressure response is with a larger horizontal pressure gradient force, which may be essential to the enhancement of BL inflow. We can understand better the RI dynamics from the perspectives of the balanced-unbalanced and symmetric-asymmetric dynamics in the full-physics cloud-resolving model simulation by the piecewise PV inversion (PPVI) diagnosis.

This paper is a follow-up work to the previous study by K19 of the Supertyphoon Haiyan RI. We employ the PPVI calculations, omega equation diagnoses, and PV and potential temperature budget analyses to quantitatively study the PV dynamics in Haiyan. Through the PPVI and omega equation diagnosis, we demonstrate that the PV mixing induced dynamical eye warming and central pressure decrease, and the increase in pressure gradient force contributes to the enhancement of unbalanced BL radial inflow and the formation of the symmetric convective PV tower in the RI processes. Section 2 describes the model data and analysis methods. The central 
pressure decrease associated with the PV mixing and dynamical eye warming are presented in section 3 . Section 4 examines the contraction of the RMW, the convective $\mathrm{PV}$ tower, and the $\mathrm{BL}$ radial inflow. Concluding remarks are given in section 5 .

\section{Data and methodology}

\section{a. Data}

Our data are from the numerical simulation of the RI in Supertyphoon Haiyan (2013), which was performed by K19 with the nonhydrostatic Cloud-Resolving Storm Simulator (CReSS; Tsuboki and Sakakibara 2002). The simulation has a 2-km horizontal resolution and 76 layers in vertical. The smallest grid spacing in the vertical is $50 \mathrm{~m}$. Model results are output every $5 \mathrm{~min}$. We also study the sensitivity of the model resolution to the peak PV values in the model convective PV tower. We also perform simulations of $1 \mathrm{~km}$ and 500-m horizontal resolutions in the present study. Due to limitations in computer resources, the high-resolution experiments are performed only for the period from 1800 UTC 7 November to 0000 UTC 8 November. The highresolution simulations are performed with a domain size of $1024 \mathrm{~km} \times 1024 \mathrm{~km}$. The initial and boundary conditions of the high-resolution experiments are based on the 2-km simulation of K19.

Typhoon Haiyan (2013) formed on 2 November 2013 in the WNP and developed in a favorable environment. It underwent RI (the intensity increased by as much as $31 \mathrm{~m} \mathrm{~s}^{-1}$ in $24 \mathrm{~h}$ ) on 5 November. The storm reached "supertyphoon" category $\left(67 \mathrm{~m} \mathrm{~s}^{-1}\right)$ based on the Joint Typhoon Warning Center (JTWC) best track data. Note that the simulation realistically captured the RI event in Haiyan except for an approximate 2-day delay in the onset time (0000 UTC 7 November 2013 in the simulation). The simulated inner-core structure exhibited qualitatively similar structure to the observed typhoon by comparison with microwave satellite images (K19).

\section{b. Estimation of inner-core pressure decrease with the PV mixing}

Hendricks and Schubert (2010) suggested possibility of decrease in the central pressure due to dynamical adjustment associated with asymmetric PV mixing, which can lead to the storm intensification. Evolution of the storm PV due to the PV mixing is estimated by a PV budget. For axisymmetric PV $(\bar{P})$, the budget equation in cylindrical coordinates $(r, \lambda, z)$, as given in Tsujino et al. (2017), is

$$
\frac{\partial \bar{P}}{\partial t}=\mathrm{AXADV}+\mathrm{ASADV}+\mathrm{DIAQ}+\mathrm{FRIC},
$$

TABLE 1. List of symbols in section 2 and the appendix.

\begin{tabular}{|c|c|}
\hline Symbol & Description \\
\hline$u, v, w$ & $\begin{array}{l}\text { Radial }(r) \text {, tangential }(\lambda) \text {, and vertical }(z) \text { wind } \\
\text { components, respectively }\end{array}$ \\
\hline$t$ & Time \\
\hline $\boldsymbol{\omega}_{a}$ & Absolute vorticity vector \\
\hline$\theta$ & Potential temperature \\
\hline$\rho_{0}$ & Horizontally averaged air density \\
\hline$\nabla$ & Three-dimensional gradient vector \\
\hline$\nabla_{h}$ & Horizontal gradient vector \\
\hline$\hat{z}$ & $=\left[1-\left(p / p_{00}\right)^{R_{d} / C_{p}}\right]\left(C_{p} \theta_{00} / g\right) ;$ pseudoheight \\
\hline$f$ & Coriolis parameter \\
\hline$p$ & Pressure \\
\hline$p_{00}$ & Reference pressure \\
\hline$\theta_{00}$ & Reference potential temperature \\
\hline$C_{p}, C_{v}$ & Specific heat capacities at fixed pressure and volume \\
\hline$R_{d}$ & Gas constant for dry air \\
\hline$g$ & Gravitational acceleration \\
\hline$\hat{\rho}$ & $=\rho_{00}\left(p / p_{00}\right)^{C_{v} / C_{p}} ;$ pseudodensity \\
\hline$\rho_{00}$ & Reference density \\
\hline$\eta$ & Absolute vertical vorticity \\
\hline$\hat{z}_{a}$ & Top of $\hat{z}\left(C_{p} \theta_{00} / g\right)$ \\
\hline$\mu$ & Ratio of $C_{v} / R_{d}$ \\
\hline$U, V$ & $x$ and $y$ components of $\mathbf{V}_{\psi}+\mathbf{V}_{\chi}$ \\
\hline
\end{tabular}

where

$$
\begin{aligned}
& \mathrm{AXADV} \equiv-\bar{u} \frac{\partial \bar{P}}{\partial r}-\bar{w} \frac{\partial \bar{P}}{\partial z}, \\
& \mathrm{ASADV} \equiv-\overline{u^{\prime} \frac{\partial P^{\prime}}{\partial r}}-\overline{v^{\prime} \frac{\partial P^{\prime}}{r \partial \lambda}}-\overline{w^{\prime} \frac{\partial P^{\prime}}{\partial z}}, \\
& \mathrm{DIAQ} \equiv-\overline{\nabla Q \cdot \frac{\boldsymbol{\omega}_{a}}{\rho_{0}}}, \\
& \mathrm{FRIC} \equiv-\overline{\nabla \theta \cdot \frac{\nabla \times \mathbf{F}}{\rho_{0}} .}
\end{aligned}
$$

The overbar and prime denote the azimuthal average and deviation from the average, respectively. AXADV and ASADV indicate the advection of PV associated with the axisymmetric and asymmetric flows, respectively. The ASADV corresponds to the redistribution of $\bar{P}$ due to the PV-mixing processes. DIAQ and FRIC mean PV generation due to diabatic heating $Q$ including microphysics, turbulence, and numerical diffusion processes and momentum sources $\mathbf{F}$ including turbulence, surface friction, and numerical diffusion processes. ${ }^{1}$ Meaning of symbols is described in Table 1 . Then $Q$ and F are directly calculated from the model output. The PV is defined as

\footnotetext{
${ }^{1}$ The term $\mathbf{F}$ does not include any asymmetric eddies resolved in the model.
} 
TABLE 2. Definition of the basic states and PV anomalies in the PV inversion and PPVI of section 2b. All variables have axisymmetric structure. Meanings of symbols are listed in Table 1.

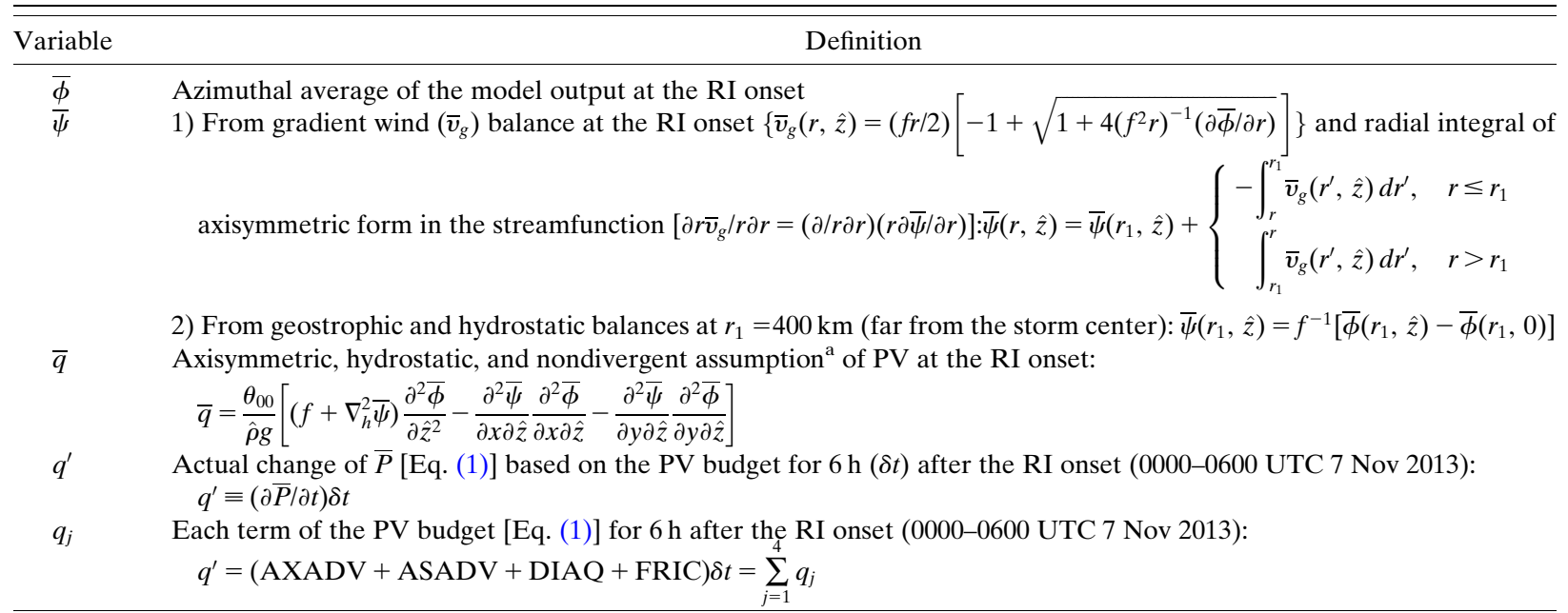

${ }^{\text {a }}$ For consistency with the PV budget analysis, the present definition does not consider effect of water vapor and condensates introduced in Wang and Zhang (2003).

$$
P \equiv \frac{\boldsymbol{\omega}_{a} \cdot \nabla \theta}{\rho_{0}}
$$

Note that tendency terms of the right-hand side (RHS) of Eq. (1) are calculated by the model output every $5 \mathrm{~min}$, and averaged over the multiple time steps during a certain period. Actual change of $\bar{P}$ on the lefthand side of Eq. (1) is calculated by the difference of $\bar{P}$ at the first and last times during the period of consideration from the calculation of the RHS terms. Thus, the budget results indicate PV change during the analysis period (not instantaneous tendency of PV).

To show the central pressure through the adjustment process associated with the PV mixing in the realistic typhoon simulation, PPVI techniques are useful for the purpose of quantification (e.g., Davis and Emanuel 1991; Wang and Zhang 2003). It is based on the invertibility principal of PV on pressure surfaces (e.g., Haynes and McIntyre 1990; Schubert et al. 2001). Under a basic state of $\mathrm{PV}$, inversion equations for dynamic and thermodynamic fields that respond to the PV anomalies are solved. When the PV change due to the PV mixing is provided as the PV anomalies, the inverted results indicate dynamic and thermodynamic fields (including pressure decrease) that respond to the PV mixing under the balanced state.

We follow the PV inversion in Wang and Zhang (2003) and PPVI in Kieu and Zhang (2010) in the present study. The inversion is based on the three-dimensional equations in horizontally Cartesian $(x, y)$ and vertically pseudoheight $(\hat{z})$ coordinates (as defined in Table 1 ), and boundary conditions. The vertical coordinate of all model variables is converted from $z$ to $\hat{z}$ through the hydrostatic relationship. The basic states of geopotential height $\bar{\phi}$, streamfunction $\bar{\psi}$, and PV $\bar{q}$ are given under the axisymmetric, hydrostatic, and gradient wind balance at the RI onset time. PV anomalies $q_{j}$ and their total $q^{\prime}$ are given by $\mathrm{PV}$ tendencies in the PV budget for $6 \mathrm{~h}$ after the RI onset (0000-0600 UTC 7 November 2013), which is summarized in Table 2. Thus, the results of the PPVI indicate response to the PV anomalies during RI under the balanced states at the RI onset. The inverted geopotential-height field corresponds to pressure change for the PV anomalies.

The PV inversion and PPVI equations are calculated on the three-dimensional space. The diagnosed geopotential height and streamfunction are axisymmetric according to Eq. (1) and Table 2. Note that the $\bar{q}$ under the balanced assumption would be different from the azimuthally averaged $\bar{P}$ based on the model output. The difference $(\bar{P}-\bar{q})$ is due to the unbalanced processes. We wish to understand the balanced-unbalanced dynamics in the azimuthally averaged sense.

\section{c. Estimation of dynamical eye warming with the asymmetric PV mixing}

On the basis of an adiabatic, three-dimensional model simulation, Hendricks and Schubert (2010) proposed that prescribed PV hollow towers can cause eye warming (referred to as dynamical eye warming) due to the transition from a ring structure to a monopole structure via low-level PV mixing. The dynamical eye warming process is in contrast to the convective eye warming due to subsidence on the inner edge of the eyewall convection (e.g., Vigh and Schubert 2009; Ohno and Satoh 2015). 
Although the present full-physics model includes both of dynamical and convective contributions, we have attempted to examine the quantitative contribution of the dynamical warming in the storm intensification.

According to Ohno and Satoh (2015), the eye warming in the simulation can be estimated by the potential temperature $(\theta)$ budget in the cylindrical coordinates:

$$
\frac{\partial \bar{\theta}}{\partial t}=\mathrm{AXADVPT}+\mathrm{ASADVPT}+\bar{Q},
$$

where

$$
\begin{aligned}
& \text { AXADVPT } \equiv-\bar{u} \frac{\partial \bar{\theta}}{\partial r}-\bar{w} \frac{\partial \bar{\theta}}{\partial z}, \\
& \text { ASADVPT } \equiv-\overline{u^{\prime} \frac{\partial \theta^{\prime}}{\partial r}}-\overline{v^{\prime} \frac{\partial \theta^{\prime}}{r \partial \lambda}}-\overline{w^{\prime} \frac{\partial \theta^{\prime}}{\partial z} .}
\end{aligned}
$$

AXADVPT and ASADVPT indicate the advection of $\theta$ associated with axisymmetric and asymmetric flows, respectively. ASADVPT corresponds to warming associated with the PV mixing. As in the PV budget, we conduct the $\theta$ budget based on the model output. However, the $\theta$ budget is difficult to diagnose purely dynamical eye warming because ASADVPT would include both of dynamical and convective eye warming. We will use the omega equation to estimate dynamically induced flows $\mathbf{V}_{D}$, and the ASADVPT contributed by $\mathbf{V}_{D}$ is dynamically induced warming in the full-physics model.

The omega equation describes vertical motions that respond to any dynamical forcing such as vorticity and thermal advection and convective forcing such as condensation heating. The forcing terms are linearly composed in the omega equation. Thus, $\mathbf{V}_{D}$ can be diagnosed by the omega equation without any convective forcing. Diagnosis of omega equation can be used to quantitatively separate contribution of the dynamically and convectively induced flows to the eye warming.

In the present study, the omega equations proposed by Wang and Zhang (2003) are used. The equations to solve unknown variables of vertical velocity $(\omega \equiv D \hat{z} / D t)$, velocity potential $\chi$, and tendency of streamfunction $\partial \psi / \partial t$ are composed as

$$
\begin{gathered}
\nabla_{h}^{2} \frac{\partial \psi}{\partial t}=-\left(\mathbf{V}_{\psi}+\mathbf{V}_{\chi}\right) \cdot \nabla_{h} \eta-\omega \frac{\partial \eta}{\partial \hat{z}}-\eta \nabla_{h} \cdot \mathbf{V}_{\chi}+\frac{\partial \omega}{\partial y} \frac{\partial U}{\partial \hat{z}}-\frac{\partial \omega}{\partial x} \frac{\partial V}{\partial \hat{z}}+\nabla_{h} \times \mathbf{F}, \\
\nabla_{h}^{2}\left(\frac{\partial^{2} \phi}{\partial \hat{z}^{2}} \omega\right)+f \eta \frac{\partial}{\partial \hat{z}}\left\{\left(\hat{z}_{a}-\hat{z}\right)^{-\mu} \frac{\partial}{\partial \hat{z}}\left[\left(\hat{z}_{a}-\hat{z}\right)^{\mu} \omega\right]\right\}-f \frac{\partial}{\partial \hat{z}}\left(\frac{\partial \omega}{\partial x} \frac{\partial^{2} \psi}{\partial x \partial \hat{z}}+\frac{\partial \omega}{\partial y} \frac{\partial^{2} \psi}{\partial y \partial \hat{z}}\right)-f \frac{\partial}{\partial \hat{z}}\left(\frac{\partial \omega}{\partial x} \frac{\partial^{2} \chi}{\partial y \partial \hat{z}}-\frac{\partial \omega}{\partial y} \frac{\partial^{2} \chi}{\partial x \partial \hat{z}}\right) \\
-\left(f \frac{\partial \eta}{\partial \hat{z}} \frac{\mu}{\hat{z}_{a}-\hat{z}}+f \frac{\partial^{2} \eta}{\partial \hat{z}^{2}}\right) \omega=f \frac{\partial}{\partial \hat{z}}\left[\left(\mathbf{V}_{\psi}+\mathbf{V}_{\chi}\right) \cdot \nabla_{h} \eta\right]-\nabla_{h}^{2}\left[\left(\mathbf{V}_{\psi}+\mathbf{V}_{\chi}\right) \cdot \nabla_{h} \frac{\partial \phi}{\partial \hat{z}}\right]-2 \frac{\partial^{2}}{\partial t \partial \hat{z}}\left(\frac{\partial^{2} \psi}{\partial x^{2}} \frac{\partial^{2} \psi}{\partial y^{2}}-2 \frac{\partial^{2} \psi}{\partial x \partial y} \frac{\partial^{2} \psi}{\partial x \partial y}\right) \\
-\frac{\partial f}{\partial y} \frac{\partial^{3} \psi}{\partial t \partial y \partial \hat{z}}+\frac{g}{\theta_{00}} \nabla_{h}^{2} Q-f \frac{\partial}{\partial \hat{z}}\left(\nabla_{h} \times \mathbf{F}\right)-\frac{\partial}{\partial t \partial \hat{z}}\left(\nabla_{h} \cdot \mathbf{F}\right), \\
\nabla_{h}^{2} \chi=-\left(\hat{z}_{a}-\hat{z}\right)^{-\mu} \frac{\partial}{\partial \hat{z}}\left[\left(\hat{z}_{a}-\hat{z}\right)^{\mu} \omega\right] .
\end{gathered}
$$

Then $\mathbf{V}_{\psi}\left(=\mathbf{k} \times \nabla_{h} \psi\right)$ and $\mathbf{V}_{\chi}\left(=\nabla_{h} \chi\right)$ are rotational and divergent components of horizontal wind, respectively. The diagnosed $\mathbf{V}_{\psi}+\mathbf{V}_{\chi}$ and $\omega$ corresponds to $\mathbf{V}_{D}$. Meaning of other symbols is summarized in Table 1 . Boundary conditions of $\omega$ at the bottom and top are given by rigid lid $(\omega=0)$.

To solve variables of $\omega, \chi$, and $\partial \psi / \partial t$ in Eqs. (4)-(6) under no heating and forcing (i.e., setting $Q=0$ and $\mathbf{F}=0$ ), information on $\psi$ and $\phi$ are required, and they are provided by the PV inversion technique as described in section $2 \mathrm{~b}$. However, the PV inversion in the omega equations is conducted every $5 \mathrm{~min}$, and the diagnosed $\mathbf{V}_{D}$ are used in the $\theta$ budget calculation. The basic states $\bar{\psi}, \bar{\phi}$, and $\bar{q}$ and total PV anomaly $q^{\prime}$ are described in Table 3. After getting perturbations $\psi^{\prime}$ and $\phi^{\prime}$ for $q^{\prime}$, the variables of $\omega, \chi$, and $\partial \psi / \partial t$ are solved with $\psi=\bar{\psi}+\psi^{\prime}$ and $\phi=\bar{\phi}+\phi^{\prime}$. Note that the $q^{\prime}$ has an asymmetric structure as defined in Table 3. Therefore, the diagnosed $\mathbf{V}_{D}$ has an asymmetric structure. In comparison of ASADVPT with flows between the model output and the diagnosis, ASADVPT with the diagnosis on the $\hat{z}$ coordinate is converted to the $z$ coordinate. The omega-based 
TABLE 3. Definition of the basic states and PV anomaly in the PV inversion of section 2c. All variables are defined at multiple time steps of the model output every $5 \mathrm{~min}$. The right column denotes if the variable has axisymmetric $(Y)$ or asymmetric $(N)$ structure.

\begin{tabular}{clr}
\hline \hline Variable & \multicolumn{1}{c}{ Definition } & AX \\
\hline $\bar{\phi}$ & $\begin{array}{c}\text { Azimuthal average of the model } \\
\text { output at the multiple time steps } \\
\text { As in Table 2, except defining at the } \\
\text { multiple time steps } \\
\bar{\psi}\end{array}$ & $Y$ \\
$\bar{q}$ & $\begin{array}{l}\text { As in Table 2, except defining at the } \\
\text { multiple time steps } \\
\text { Difference of PV between the model- } \\
\text { based } P \text { in Eq. }(2) \text { and } \bar{q} \text { under axi- } \\
q^{\prime}\end{array}$ & $Y$ \\
& $\begin{array}{l}\text { symmetric balance at the multiple } \\
\text { time steps }\left(q^{\prime} \equiv P-\bar{q}\right)\end{array}$ & \\
\hline
\end{tabular}

ASADVPT provides the information on dynamical eye warming.

\section{Potential vorticity diagnosis}

\section{a. Overview of the Haiyan (2013) simulation in the CReSS model}

Figure 1 shows the evolution of the storm central pressure, axisymmetric parameter of PV (Miyamoto and Takemi 2013; K19), and warm-core parameter that is defined as the temperature difference between the storm center and the azimuthal average at a radius of $400 \mathrm{~km}$, in the simulation. Although the RI-onset time was based on the increasing rate of surface wind speed in K19, the evolution of the central pressure was also tracking the intensification. On the basis of the different changing rate of central pressure, four different periods are defined as ST-I (1400 UTC 6 November0000 UTC 7 November 2013), ST-II (0000-1200 UTC 7 November), ST-III (1200-1800 UTC 7 November 2013), and ST-IV (1800 UTC 7 November-0000 UTC 8 November 2013) in the present study (Fig. 1a). The RI end was 0000 UTC 8 November 2013 (K19). The central pressure reflects the amplitude and vertical structure of the warm core via the hydrostatic balance (e.g., Chen and Zhang 2013). Evolution of the warm core is essential for the intensification processes.

The central pressure gradually decreased during ST-I while the PV field acquired a nearly axisymmetric structure (Fig. 1a). The axisymmetric parameter maintained itself after this period with a gradual increase. The height of the warm-air region gradually descended, with slight enhancement of the 3-6-km heights (Fig. 1b). After the RI onset, the decreasing rate of the central pressure became large, which coincided with an enhancement of peak warm core values from 4 to $6 \mathrm{~K}$.
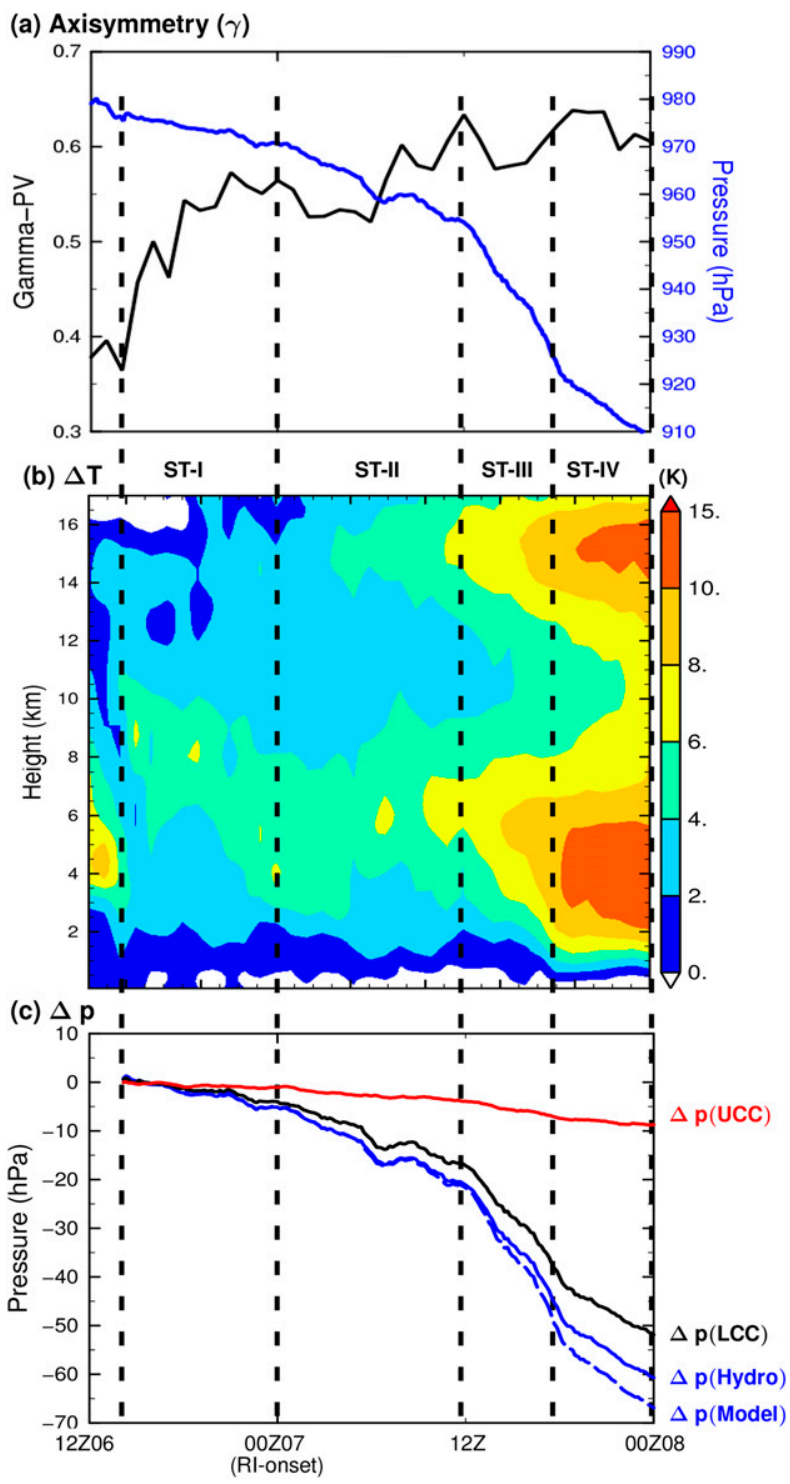

FIG. 1. (a) Time series of the simulated central pressure (blue) and the PV axisymmetric parameter (black) by Miyamoto and Takemi (2013), (b) time-height cross section of temperature anomaly at the storm center (colors; K), and (c) time series of the central pressure decreases by model output (blue dashed line), hydrostatic balance (blue solid line), and contribution of the lower warm core (black line) and upper warm core (red line) from the start of ST-I (1400 UTC 6 Nov 2013) in the simulation. The temperature anomaly is defined as temperature difference between the storm center and azimuthal average at a radius of $400 \mathrm{~km}$ from the storm center. The RI-onset time was defined by increasing rate of surface wind speed in K19. The contribution of the lower (below a height of $11 \mathrm{~km}$ ) and upper (above the height of $11 \mathrm{~km}$ ) cores is estimated by a similar method to Zhang and Chen (2012) as described in the appendix.

In ST-III, the central pressure quickly deepened from 955 to $920 \mathrm{hPa}$ in $6 \mathrm{~h}$ and the storm center experienced significant warming at heights between 1 and $7 \mathrm{~km}$. The warm core peak values increased from 6 to $10 \mathrm{~K}$. In the 
$1-5-\mathrm{km}$ heights, the warming was the largest during the RI period. In the later stage of ST-IV, the pressure deepening and warming became more gradual than that in ST-III, except for the height above $8 \mathrm{~km}$. The peak height of the low-level warm anomaly is different from many previous studies in that the warm anomalies in these studies are with a higher altitude (e.g., Halverson et al. 2006; Zhang and Chen 2012; Chen and Zhang 2013; Vigh and Schubert 2009; Ohno and Satoh 2015). ${ }^{2}$ Recently, an aircraft observation captured local peak of warm anomaly at a $3-\mathrm{km}$ height in the eye of Typhoon Lan (2017) during the mature stage using dropsonde (Fig. 4a in Yamada et al. 2018). Such a low-level warm anomaly was also found in hurricanes [e.g., Fig. 10 in Hendricks and Schubert (2010) or in Willoughby (1998)]. Our simulation is in general agreement with Yamada et al. (2018) and Hendricks and Schubert (2010).

The simulated storm had another peak of the warm anomaly in a layer of 11-16-km heights in the ST-III and ST-IV stages, which is referred to as double warm cores (e.g., Kieu et al. 2016). The central pressure decrease due to the upper-core warming was smaller than that of the lower core in ST-I and ST-II ${ }^{3}$ (Fig. 1c), which was estimated by a similar method to Zhang and Chen (2012) in the appendix. Therefore, we focus on the PV mixing and associated formation of the lower core around the RI onset (ST-I and ST-II).

\section{b. PV fields}

The simulated storm achieved the PV-axisymmetry value of 0.5 by 1800 UTC 6 November 2013 (Fig. 1a). Thus, we consider the storm to be essentially axisymmetric at that time. In ST-I, axisymmetric PV is concentrated in $5-8-\mathrm{km}$ heights at the center, which corresponds to a monopole structure of PV (Fig. 2a). The monopole PV also had high static stability, consistent

\footnotetext{
${ }^{2}$ Following a reviewer's comment, we examine the definition of the model reference temperature. The reference temperature profile, as the azimuthally averaged temperature at a radius of $400 \mathrm{~km}$ from the center, is in general agreement with sounding profiles at nearby stations. The observed soundings and model reference temperature profile are provided in the online supplemental material (see "Supplemental Material 1").

${ }^{3}$ The upper-core contribution to the central pressure decrease was insignificant in ST-III and ST-IV (Fig. 1c) because the depth of the upper core is much shallower than that in the lower core. The amplitude of the temperature anomaly in the upper core, however, is not much different from that in the lower core. The inflow-layer feature is in general agreement with a previous study (Kieu et al. 2016). Kieu et al. (2016) suggested that the inflow layer can be attributed to the atmosphere-cloud radiation process. Our simulation, however, did not use any atmosphere-cloud radiation schemes. The model upper-warm-core structure is in the online supplemental material (see "Supplemental Material 2").
}

with concentration of isentropic surfaces. The warm core is located above the region of concentrated PV (Fig. 1b). On the other hand, the peak of PV in 1-4-km heights located at a $20-\mathrm{km}$ radius, corresponds to a ringlike structure of PV. The structure at low levels suggests possibility of PV mixing due to an instability. Thus, the horizontal PV field also possessed significant polygonal structure at the $315-\mathrm{K}$ potential temperature level at $2.5-\mathrm{km}$ height (Fig. 2e).

Six hours later, the axisymmetric PV at low levels had increased near the storm center (Fig. 2b). This increase of high PV in the center was due to PV inward advection to the center (Fig. 2f). The midlevel monopole PV structure at the center (Fig. 2a) in ST-I had almost disappeared, and another peak developed in $20-30-\mathrm{km}$ radii at the same height (Fig. 2b). Coinciding with the low-level monopole PV, isentropic surfaces were concentrated in 2-4-km heights near the center. The warm core was also located above the concentrated isentropic surfaces (Fig. 1b). In addition to the PV inward advection at low level, the horizontal $\mathrm{PV}$ field had a convective-coupled ring shape with relatively high-PV values over 20 PVU (Fig. 2f). The ring-shaped high PV field resembles to the convective PV tower in the axisymmetric model of Hausman et al. (2006).

After the RI onset, the axisymmetric PV field had a taller structure than that at the RI onset around radii of 20-40 km (Fig. 2c). This structure is similar to hollow PV towers in Hausman et al. (2006), except for relatively smaller PV values. Moreover, the PV increased near the center in the vertical layers from the surface to $2 \mathrm{~km}$ and from 3 to $6 \mathrm{~km}$ (Fig. 2c). The isentropic PV map (Fig. 2g) indicated the convective $\mathrm{PV}$ towers with more high-PV value (>50 PVU), and the high PV in the eyewall was actively transported into the storm center.

Eventually, the PV field became an almost monopole structure with peak values around 70 PVU in lower troposphere centered at the 315-K level (Figs. 2d,h). On the other hand, the axisymmetric PV had a significant convective PV tower in middle and upper troposphere (Fig. 2d). The structure is similar to the PV bridge in Yau et al. (2004). The time variation of the PV fields indicates that the storm experienced active PV mixing associated with a significant ringlike structure that was dynamically unstable during ST-I and ST-II. Thus, a PV budget analysis on the axisymmetric view of Eq. (1) can clarify the influence of the PV mixing on the intensification around the RI onset (ST-I and ST-II).

\section{c. PV budget}

In ST-I, active PV mixing occurred around the 315-K level. The PV in the center is relatively smaller than that outside the center, and the outside PV has elliptical or 
(a) PV [PVU] $]_{(18: 00: 00 Z 06 \text { Nov2013) }}$

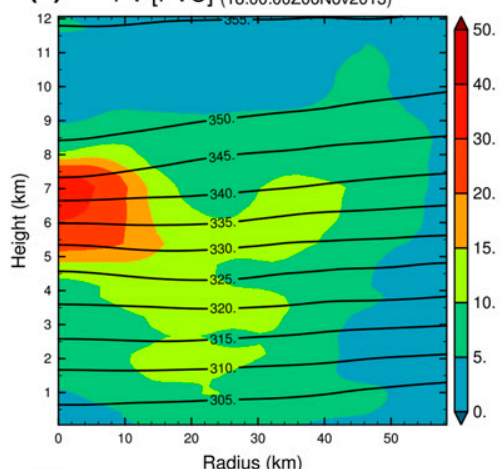

(b) PV $[\mathrm{PVU}]_{(00: 00: 00 Z 07 \text { Nov2013) }}$

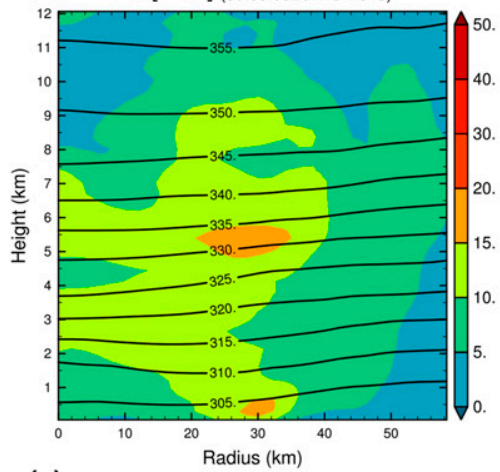

(c) PV $[\mathrm{PVU}]_{(06: 00: 00 Z 07 \text { Nov2013) }}$

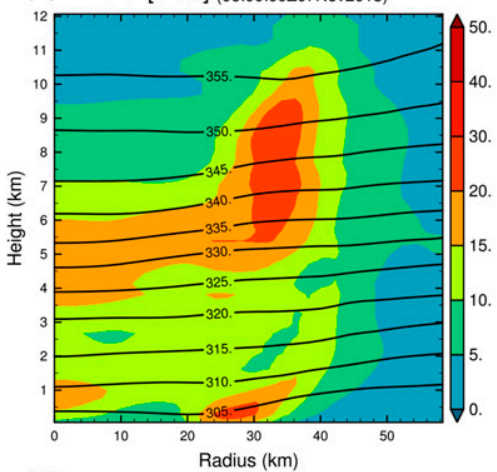

(d) PV $[\mathrm{PVU}]_{(18: 00: 00 Z 07 \text { Nov2013) }}$

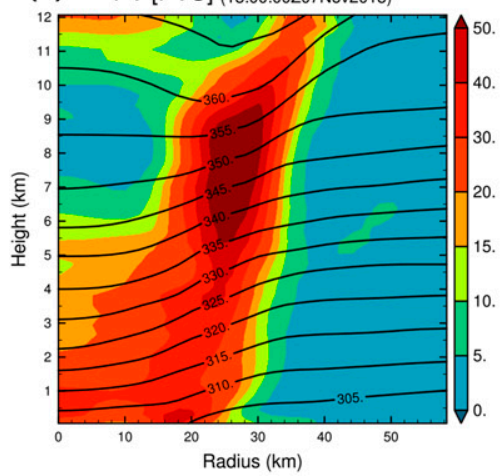

(e)

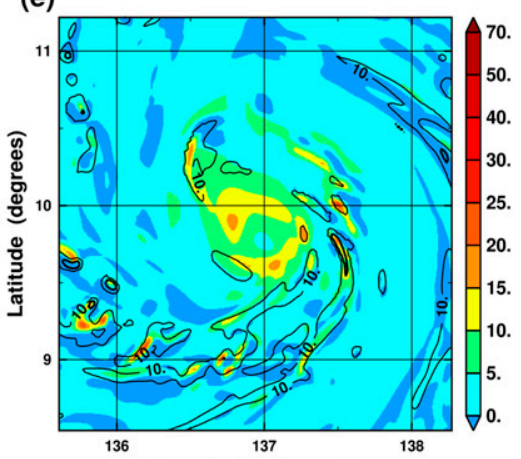

(f)

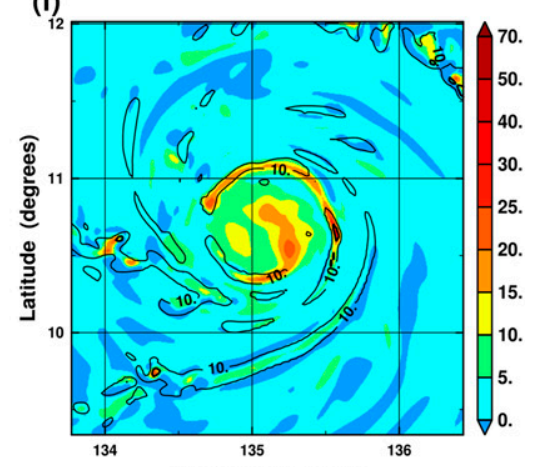

(g)

Longitude (degrees)

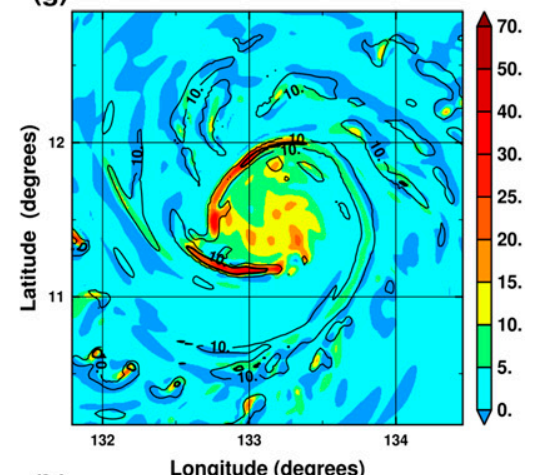

(h)

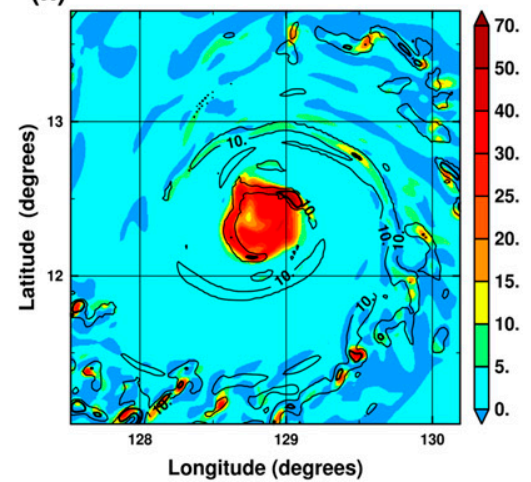

FIG. 2. (left) Radius-height cross sections of azimuthally averaged PV (colors; PVU) and potential temperature (contours; K), and (right) horizontal distributions of PV (colors; PVU) and diabatic heating (thin contours $10 \mathrm{~K} \mathrm{~h}^{-1}$; thick contours: $100 \mathrm{~K} \mathrm{~h}^{-1}$ ) on the 315-K isentropic surface at (a),(e) 1800 UTC 6 Nov, (b),(f) 0000 UTC 7 Nov, (c),(g) 0600 UTC 7 Nov, and (d),(h) 1800 UTC 7 Nov 2013. 

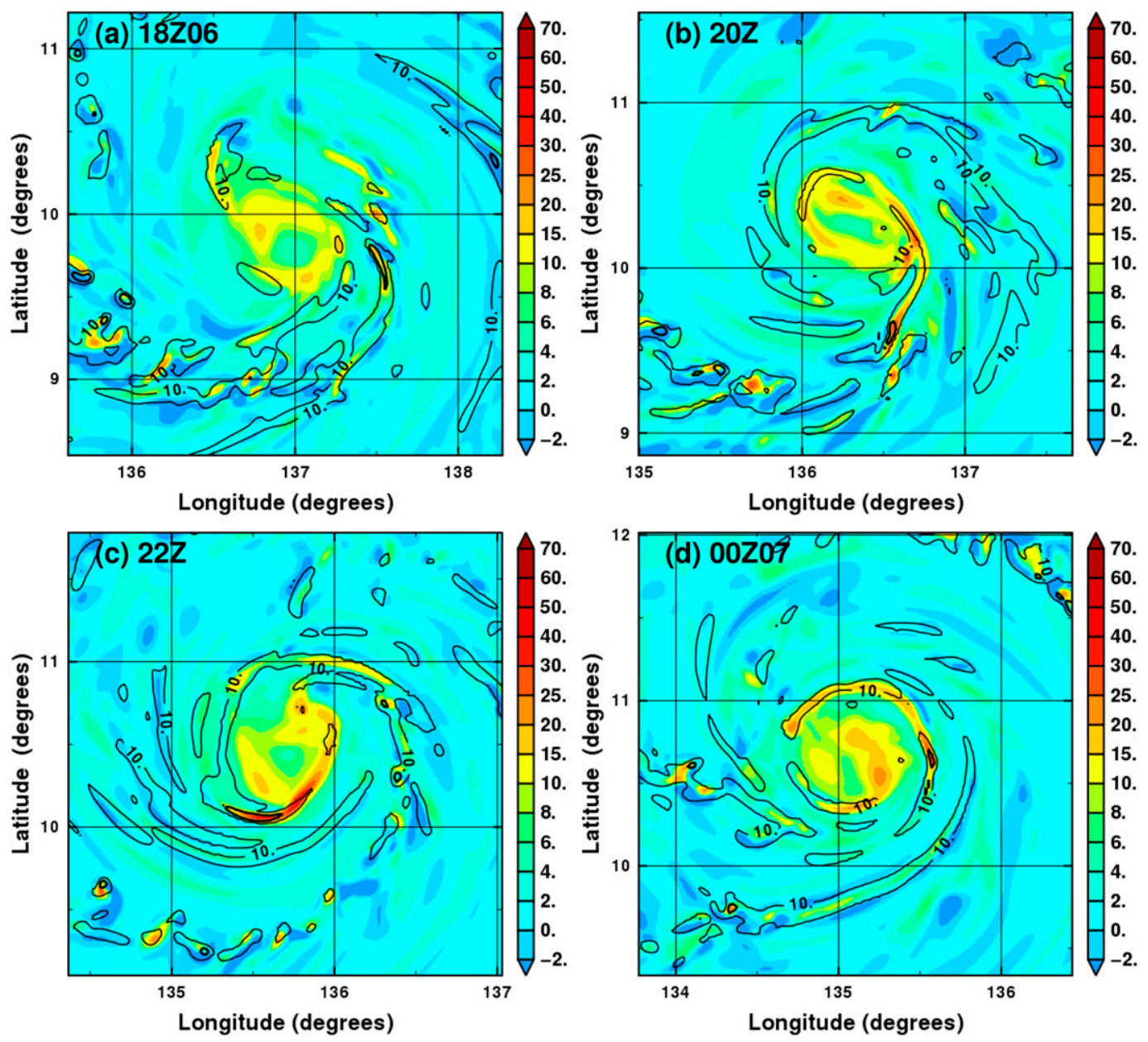

FIG. 3. Horizontal distribution of PV (colors; PVU) and diabatic heating (thin contours: $10 \mathrm{~K} \mathrm{~h}^{-1}$; thick contours: $100 \mathrm{~K} \mathrm{~h}^{-1}$ ) on the $315-\mathrm{K}$ isentropic surface (near a height of $2 \mathrm{~km}$ ) at (a) 1800 UTC 6 Nov, (b) 2000 UTC 6 Nov, (c) 2200 UTC 6 Nov, and (d) 0000 UTC 7 Nov 2013 (at the RI onset).

polygonal shapes (Fig. 3). High-PV towers were associated with diabatic heating in the eyewall updraft, suggesting PV generation due to the diabatic heating (Figs. 3b-d). Eventually, the PV towers concentrate to the storm center at the RI onset (Fig. 3d).

Figure 4 shows results of the PV budget from 1800 UTC 6 November to 0000 UTC 7 November 2013, corresponding to Fig. 3 . The storm had a positive PV region with above 10 PVU around a radius of $30 \mathrm{~km}$ below an $8-\mathrm{km}$ height. The actual change (i.e., $\partial \bar{P} / \partial t$ ) shows a positive tendency in the same radius, and a part of the positive tendency goes along with the positive PV (Fig. 4a). Another positive PV tendency appears in the layer from 2 to $4 \mathrm{~km}$ in the eye, consistent with the PV evolution in Figs. 2a and 2b. In addition, the storm exhibited a negative PV tendency near the center in 4$8-\mathrm{km}$ height range. The structure of the actual change is similar to that in the sum of the RHS in Eq. (1), as shown in Fig. 4b. The difference between PV budget and actual change is smaller than $4 \mathrm{PVU}$ in the 6-h period. Most of the difference occurred within the $\mathrm{BL}$ at radii of $20-40 \mathrm{~km}$ and above the BL outside the $30-\mathrm{km}$ radius (Fig. 4c), which is mostly along the eyewall updraft (Fig. 4j). The discrepancies within 4 PVU indicates the budget results can reasonably diagnose the actual change of PV in the eye region. In addition, FRIC did not significantly influence the PV tendency (Fig. 4g).

The two regions of the positive $\partial \bar{P} / \partial t$ and one negative region were mainly caused by advection due to asymmetric flows (ASADV) below $8 \mathrm{~km}$ (Fig. 4e). The positive $\partial \bar{P} / \partial t$ above $8 \mathrm{~km}$ in the $20-40-\mathrm{km}$ radii was dominated by the PV generation due to diabatic heating (DIAQ) in the eyewall (Fig. 4f). The axisymmetric advection of PV (AXADV) did not significantly influence the positive $\partial \bar{P} / \partial t$ (Fig. $4 \mathrm{~d}$ ). In the two regions of the positive $\partial \bar{P} / \partial t$, the positive ASADV corresponds to 
(a) Actual change

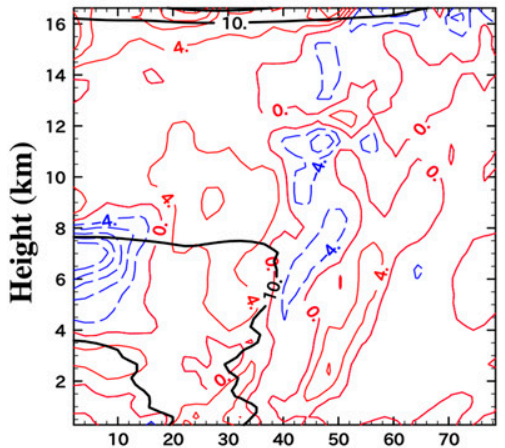

(d) AXADV

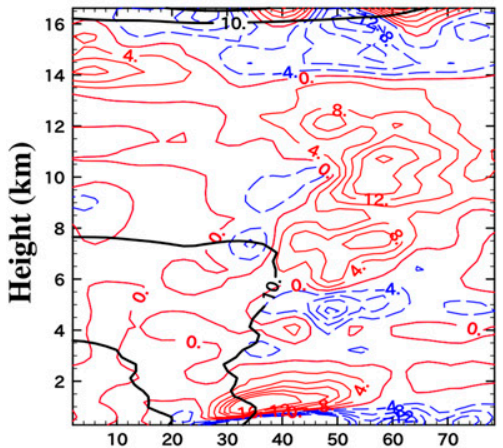

(g) FRIC

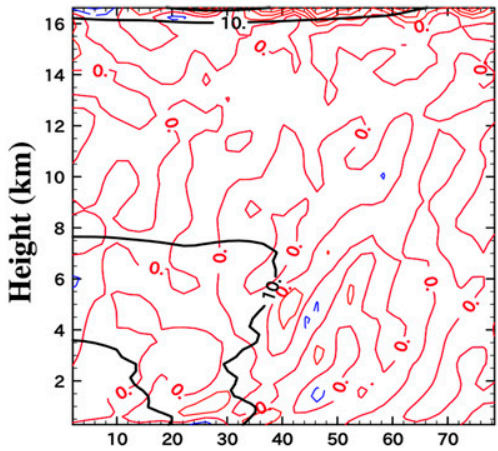

(j) Heat and W

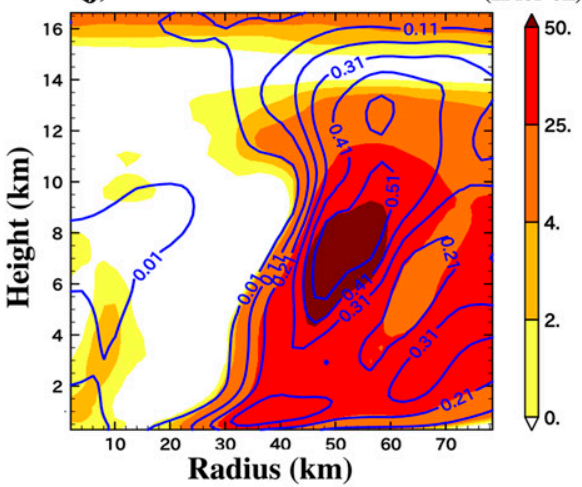

(b) Sum of RHS

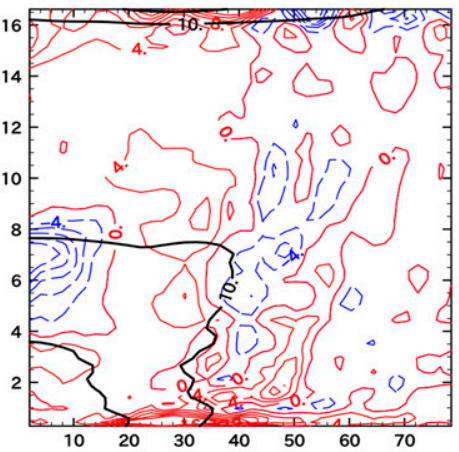

(e) ASADV

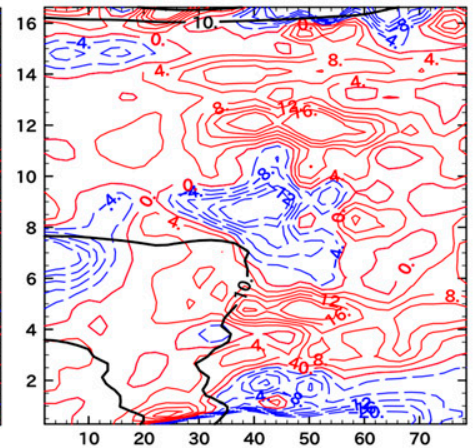

(h) AXDIAQ

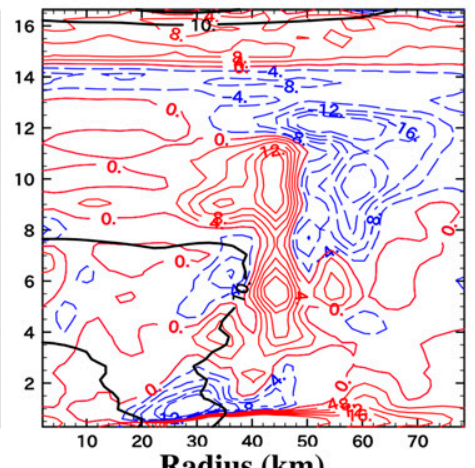

(c) Diff. (a) - (b)

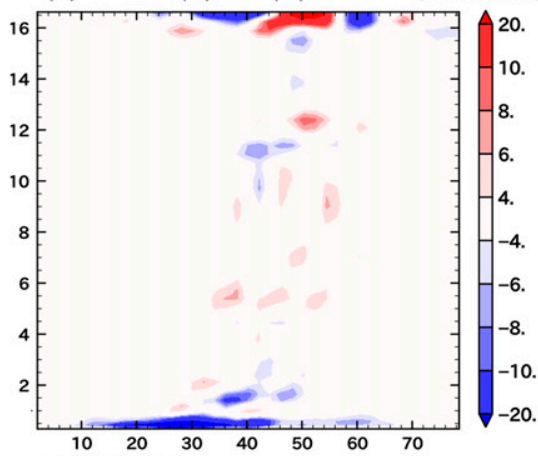

(f) DIAQ

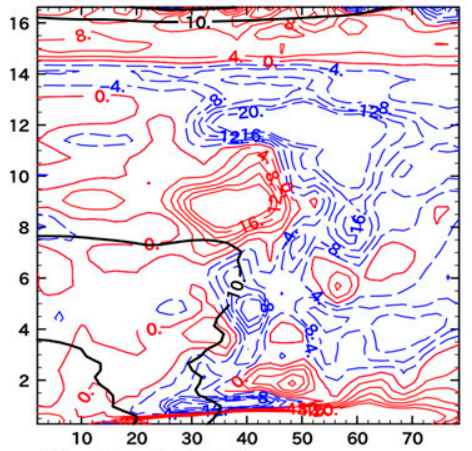

(i) AXADVZ

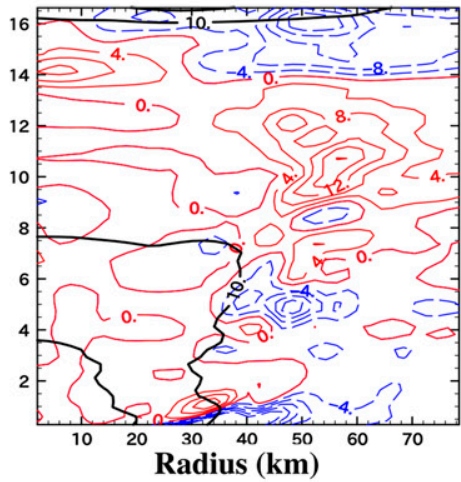

FIG. 4. Radius-height cross section of (a) actual change $(\partial \bar{P} / \partial t)$, (b) sum of the right-hand side of Eq. (1), (c) difference (color; PVU for $6 \mathrm{~h}$ ) between (a) and (b), (d) PV advection due to axisymmetric flow, (e) PV advection due to asymmetric flow, (f) PV generation due to diabatic heating, (g) PV generation due to momentum sources, (h) axisymmetric components in (f), (i) axisymmetric vertical advection in the PV budget analysis during 1800 UTC 6 Nov to 0000 UTC 7 Nov 2013 (color contours; PVU for $6 \mathrm{~h}$ ), and (j) temporally averaged diabatic heating (colors; $\mathrm{K}$ for $6 \mathrm{~h}$ ) and vertical velocity (blue contours; $\mathrm{m} \mathrm{s}^{-1}$ ) from 1800 UTC 6 Nov to 0000 UTC 7 Nov 2013. Color contours in the PV budget panels signify temporal variation of PV over $6 \mathrm{~h}$. Black contour denotes $\bar{P}$ (PVU) averaged over $6 \mathrm{~h}$. 

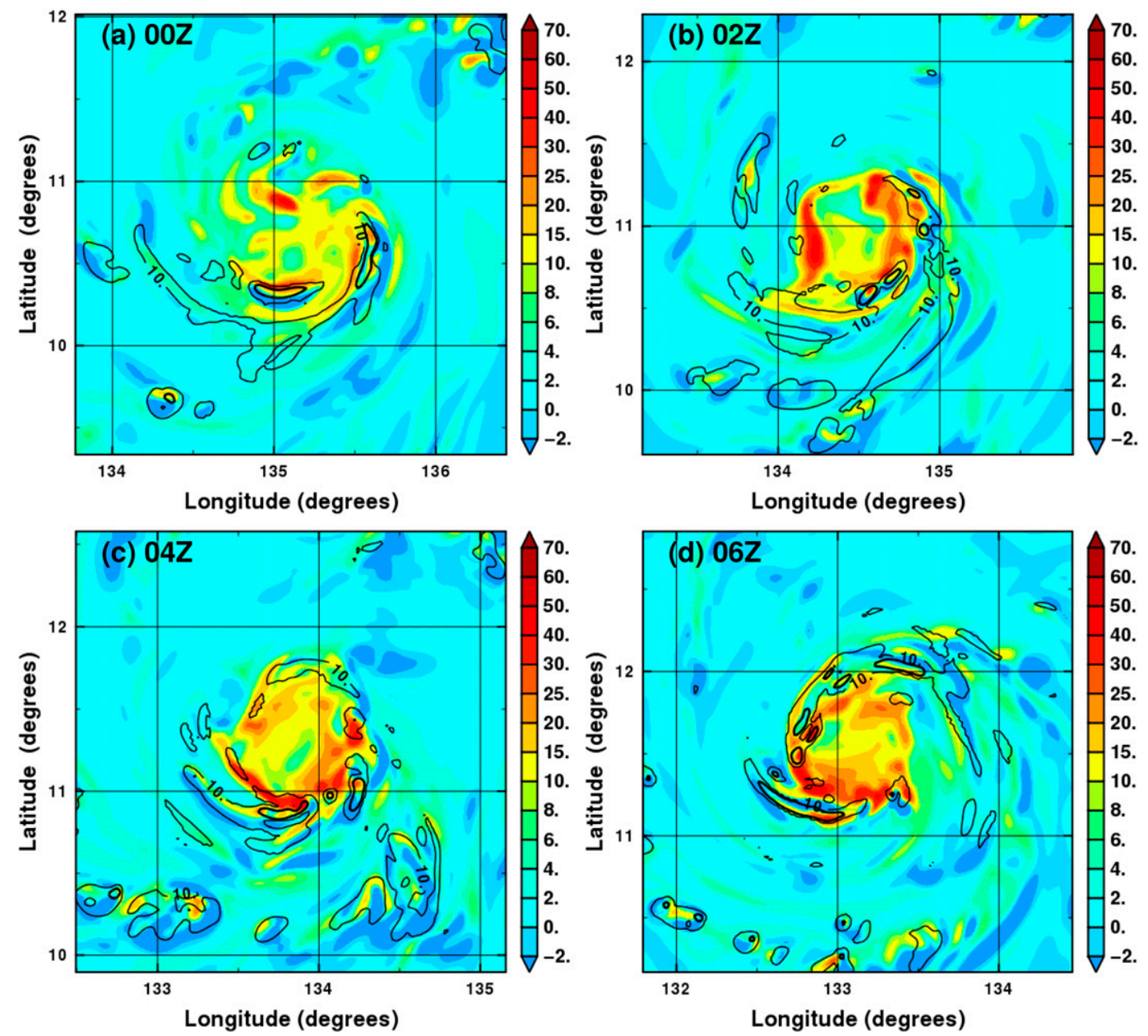

FIG. 5. As in Fig. 3, but at the 340-K isentropic surface (near a height of $6 \mathrm{~km}$ ) at (a) 0000, (b) 0200, (c) 0400, and (d) 0600 UTC 7 Nov 2013 (after the RI onset).

spatial redistribution of PV due to PV mixing. Note that the PV mixing was dynamically and convectively induced in the present model with full physics, unlike the context in previous barotropic or isentropic models without convective forcing (e.g., Hendricks et al. 2009; Hendricks and Schubert 2010). The positive ASADV in the eye below the height of $4 \mathrm{~km}$ suggests similar mixing from barotropic instability.

A local positive peak of DIAQ is exhibited at $40-\mathrm{km}$ radius and at 9-km height (Fig. 4f). The DIAQ term has a positive peak beneath a peak height of diabatic heating from Eq. (1), and the axisymmetric component (AXDIAQ) of DIAQ is largely cancelled with vertical advection of PV due to axisymmetric flows (AXADVZ). The positive peak of DIAQ and AXDIAQ in the storm (Figs. 4d,h) was located beneath a local peak of the diabatic heating at a $12-\mathrm{km}$ height around a $40-\mathrm{km}$ radius (Fig. 4j). However, the positive AXDIAQ was cancelled with negative ASADV (Fig. 4e). The AXDIAQ in the storm had another positive peak around the $5-\mathrm{km}$ height and at $40-\mathrm{km}$ radius (Fig. $4 \mathrm{~h}$ ) in corresponding to the diabatic heating peak at the 7-km height in the eyewall (Fig. 4j). The AXDIAQ was overcome by asymmetric component of DIAQ, as shown in negative region of the DIAQ distribution (Fig. 4f). The storm did not have large cancellation between the axisymmetric components in the PV generation and advection.

In ST-II, active PV mixing was suggested around the 340-K level. Horizontal distribution of the PV is still associated with individual convection at the RI onset (Fig. 5a), but it is close to an elliptical or polygonal shape with hollow PV towers during $6 \mathrm{~h}$. As in ST-I, high PV in the towers were associated with diabatic heating in the eyewall (Figs. 5b-d). Moreover, the high PV in the eyewall was entrained to the center.

Figure 6 shows the budget results from 0000 to 0600 UTC 7 November 2013, corresponding to Fig. 5. The storm had a PV peak with 20 PVU around a radius 
(a) Actual change

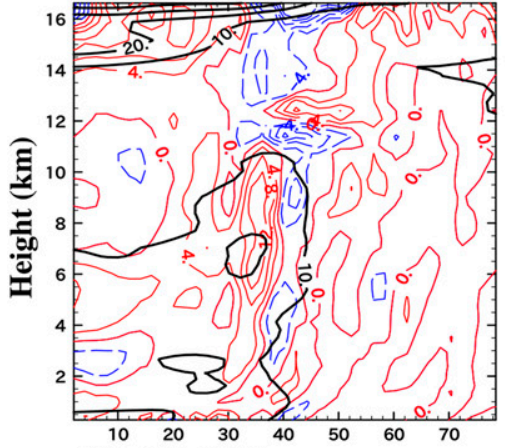

(d) AXADV

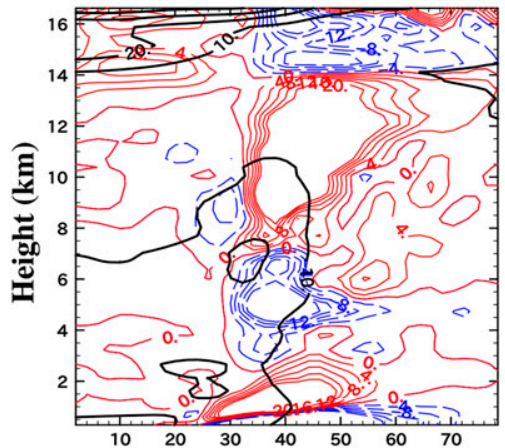

(g) FRIC

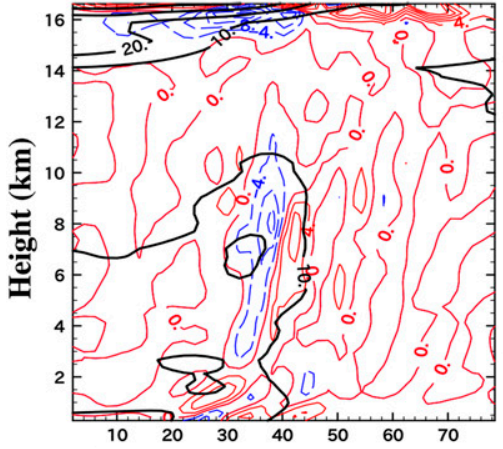

(j) Heat and W (b) Sum of RHS

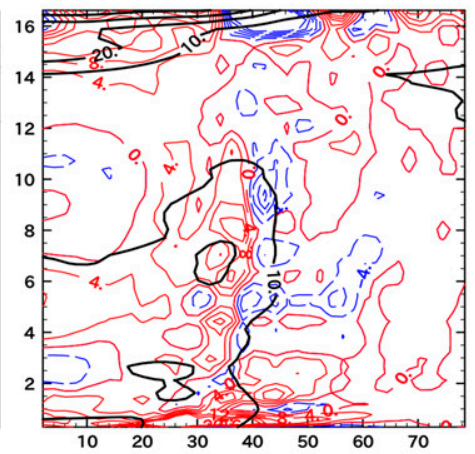

(e) ASADV

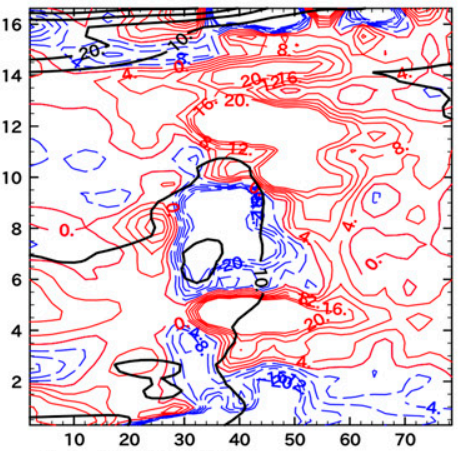

(h) AXDIAQ

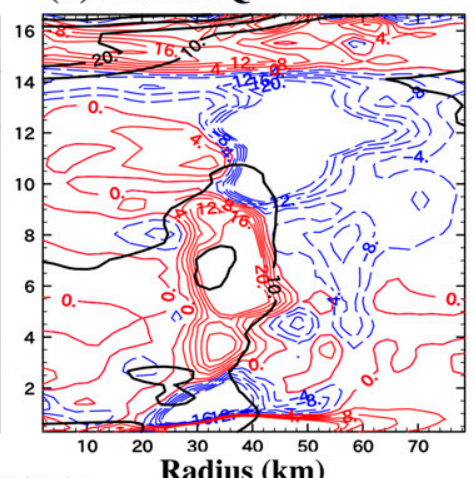

(K for $6 h$ ) (c) Diff. (a) - (b)

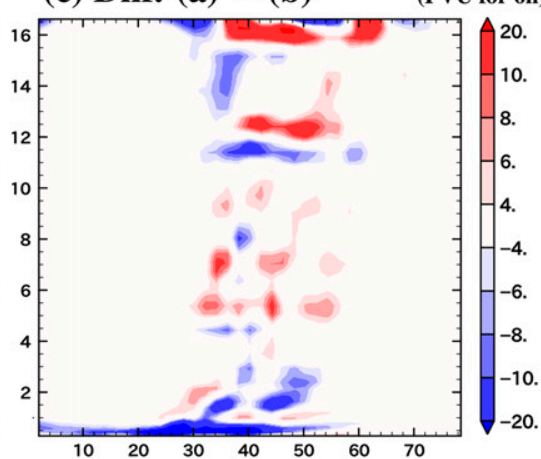

(f) DIAQ

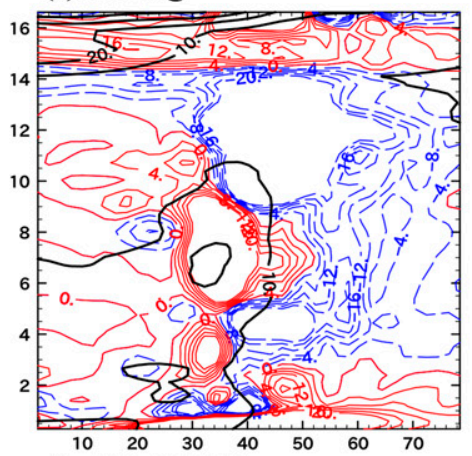

(i) AXADVZ

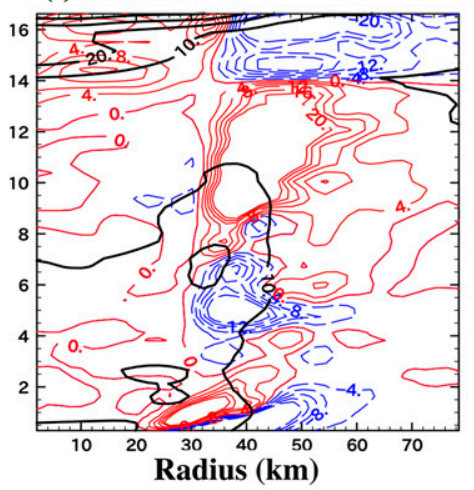

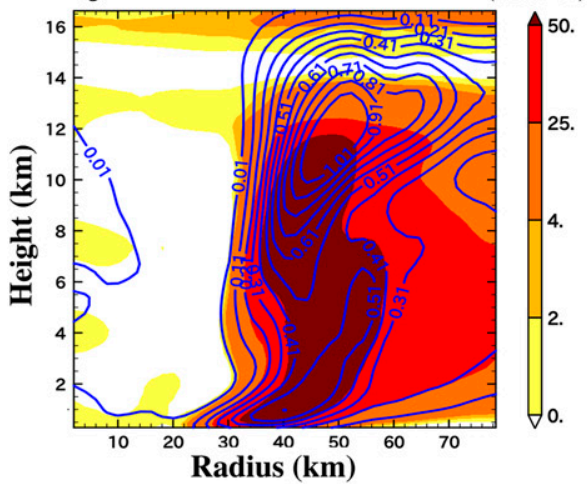

FIG. 6. As in Fig. 4, but for 0000-0600 UTC 7 November 2013 (after RI onset). 
of $30 \mathrm{~km}$. This peak associated with the eyewall corresponds to the hollow PV tower in the axisymmetric view. The $\partial \bar{P} / \partial t$ shows the positive tendency along the PV tower (Fig. 6a). Another positive tendency appears in the vertical layer from 4 to $7 \mathrm{~km}$ within a radius of $20 \mathrm{~km}$. The positive region along the tower is continuously linked to the other positive region in the eye. General feature of accuracy in the PV budget is similar to that in ST-I (Fig. 4c). The budget results can reasonably reproduce $\partial \bar{P} / \partial t$ within $4 \mathrm{PVU}$ for $6 \mathrm{~h}$ in the eye (Figs. 6a-c). FRIC did not largely influence the PV tendency (Fig. 6g).

The positive $\partial \bar{P} / \partial t$ along the PV tower in the eyewall is mainly caused by DIAQ below a height of $9 \mathrm{~km}$ and AXADV above that height (Figs. 6d,f) with noting overlap between the PV tower. The DIAQ and AXADV are mainly dominated by AXDIAQ and AXADVZ, respectively, and largely cancelled with each other along the PV tower (Figs. $6 \mathrm{~h}-\mathrm{j}$ ). Thus, the positive value of $\partial \bar{P} / \partial t$ is much less than the positive values in the DIAQ and AXADV. Moreover, the large positive values along the eyewall were cancelled with negative ASADV except in the vertical layer from 4 to $5 \mathrm{~km}$ (Fig. 6e). On the other hand, ASADV had a positive region in the inner side of the negative peak along the PV tower. The positive region was below $9 \mathrm{~km}$, and expanded to the center in a layer from 4 to $7 \mathrm{~km}$. The expanded positive ASADV almost completely accounts for the positive $\partial \bar{P} / \partial t$ near the center (Figs. 6a,e). The unique pattern of ASADV, which has a positive contribution in the inside edge and in the eye and a negative contribution in the region of the convective PV tower, provides the picture of how eddy processes extract excess PV from the convective PV tower and deposit it in the inside regions.

\section{d. Pressure deepening due to $P V$ mixing}

The PV budget revealed that the PV mixing (ASADV) mainly contributed to the PV tendency near the storm center around the RI onset. Using a PPVI technique, we show that the PV mixing can also influence the central pressure reduction. During 0000-0600 UTC 7 November 2013 (i.e., after the RI onset), the simulated storm showed actual reduction of axisymmetric geopotential height within a radius of $50 \mathrm{~km}$ below $14 \mathrm{~km}$, and had the maximum decrease $(<-80 \mathrm{~m})$ at the storm center at low levels (Fig. 7a). The actual reduction of the geopotential height had large vertical gradients in layers of $5-8 \mathrm{~km}$ and $12-14 \mathrm{~km}$ near the center. These are consistent with the lower and upper peaks of warm anomaly (Fig. 1b) as expected in the hydrostatic balance of $\partial \phi / \partial \hat{z}=g\left(\theta / \theta_{00}\right)$. In addition, large radial gradient of the geopotential

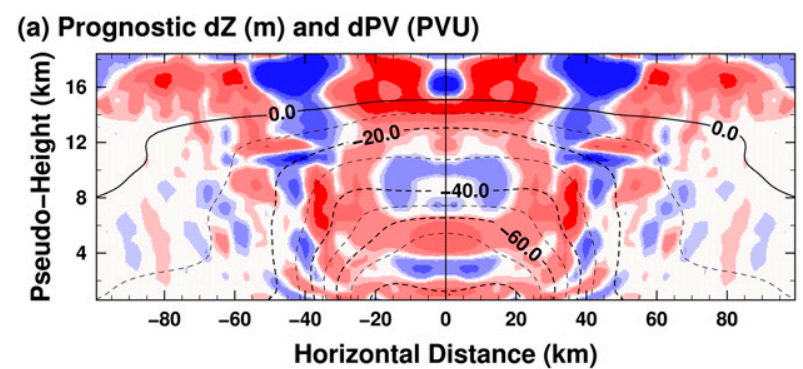

(b) Diagnostic dZ (m) and dPV (PVU)

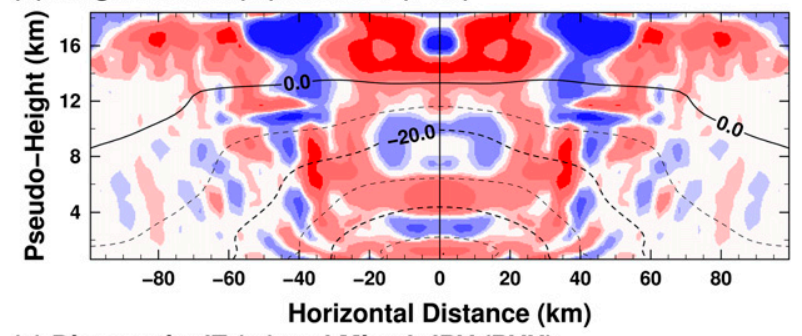

(c) Diagnostic dZ (m) and Mixed-dPV (PVU)

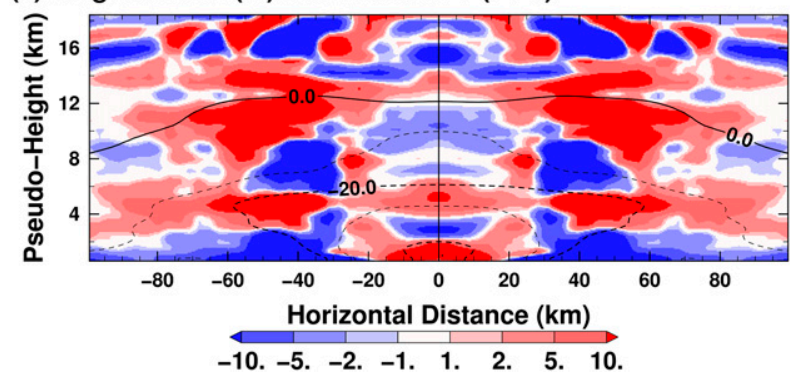

FIG. 7. Spatial distributions of geopotential height (contours; $\mathrm{m}$ ) falls and PV tendencies (colors; PVU) during 0000-0600 UTC 7 Nov 2013 corresponding to (a) actual geopotential height falls and (b) diagnosed geopotential height falls associated with the actual PV tendency shown in (a). (c) The geopotential height falls associated with the PV tendency due to the PV mixing (i.e., ASADV in the PV budget).

height decrease is exhibited around radii of $20-40 \mathrm{~km}$ at the low levels.

Coinciding with the actual PV change during the same period, decrease in the geopotential height is diagnosed with the PPVI technique on the axisymmetric gradientwind balanced state, which does not include any transient processes (Fig. 7b). The diagnosed decrease was dominated in the inner core below $14 \mathrm{~km}$, and the maximum decrease $(<-50 \mathrm{~m})$ was at the storm center at low levels. The radial gradient of the geopotentialheight decrease around the $20-40-\mathrm{km}$ radii at the low levels is more moderate than that of the actual change. As mentioned in section $2 b$, difference of the axisymmetric PV field between the model output and balance state $(\bar{P}-\bar{q})$ is not included in the total PV anomaly $q^{\prime}$. Thus, the difference of the decrease in the geopotential height between Figs. $7 \mathrm{a}$ and $7 \mathrm{~b}$ can be caused by the imbalance and transient processes, which accounts for 
the decrease in the geopotential height of about $35 \%$ at the center.

We quantitatively examine the decrease in geopotential height due to the ASADV. The diagnosis shows a clear decrease in the geopotential height in the inner core below $12 \mathrm{~km}$ (Fig. 7c). Similar to Fig. 7b, the maximum decrease $(<-40 \mathrm{~m})$ was at the storm center at low levels, which accounts for the decrease in the geopotential height of about $50 \%$ at the center. Moreover, the decrease in the geopotential height had large peaks in layers of 4-6 and 9-12 km. It suggests large warming associated with the ASADV. On the other hand, the ASADV includes dynamically and convectively induced asymmetric flows as mentioned in section $2 \mathrm{c}$. To show the dynamical eye warming associated with the PV mixing, we separate the asymmetric flows between dynamical and convective components in the next section.

There were several PV mixing episodes occurred in low and midlevels of the free atmosphere before and after the RI onset in the simulation (Figs. 4 and 6). When the storm is weak, the Rossby radius of deformation is large and the Rossby height is small. The PV mixing may not induce significant pressure decrease (less mass response in the geostrophic adjustment). Moreover, the pattern of pressure decrease in the weaker storm is elongated horizontally with a smaller horizontal pressure gradient. When the storm reached to a sufficient strength, the deformation radius becomes small and the Rossby height becomes deep (Kieu and Zhang 2010). This will lead to a more significant pressure decrease with a larger horizontal gradient. The large horizontal pressure gradient from the PV mixing can be essential to the enhancement of BL inflow.

\section{e. Dynamically induced eye warming}

The PV mixing limited to low levels also causes a PV bridge structure (Fig. 2b), which is composed of a monopole PV above the BL in the eye and a hollow PV tower in the eyewall (e.g., Yau et al. 2004). It suggests dynamical eye warming. Figure 8 shows results of the $\theta$ budget based on three-dimensional flows by the model output and omega equation diagnosis. In ST-I the storm had clear warming in 3-6-km layer, and cooling in 79-km layer near the center (Fig. 8a). This pattern corresponds to a descending of the midlevel warm core (Fig. 1b). The warming was located above the increasing region of PV near the storm center (Fig. 4a). Another warming above a $12-\mathrm{km}$ height corresponding to the upper warm core was mainly caused by the axisymmetric adiabatic warming (Fig. 8e). In ST-II, the storm had clear warming in 1-2.5-km layer and above $6 \mathrm{~km}$ near the center (Fig. 8b). The warming was located above the PV increasing regions (Fig. 6a).
The warming in the lower to middle troposphere in both periods can largely be interpreted by asymmetric advection of $\theta$ (ASADVPT) corresponding to the PV mixing (Figs. 8a,b,i,j). ASADVPT diagnosed by the omega equations had warming in similar levels near the center as the model-based ASADVPT (Figs. 8m,n). In ST-II, the warming layers in 5-7 and 8-11 km near the center mostly corresponds to the layers with large vertical gradient of the decrease in the geopotential height associated with the PV mixing, particularly (Fig. 7c). Thus, the eye warming was dynamically induced by the PV mixing around the RI onset. Note that the warming values due to the mixing are always stronger than the actual warming. The warming is partly cancelled out by adiabatically axisymmetric cooling (Figs. 8e,f).

A local warming band of the model-based ASADVPT appears in the middle troposphere (almost corresponding to melting layer) outside the eye in all stages (Figs. 8i-1). We consider that the warming can be associated with vertical motions at the convective scale in the eyewall and rainbands. The air mass associated with the convective-scale compensating subsidence $\left(w^{\prime}<0\right)$ in the eyewall and rainbands updrafts mostly keeps $\theta^{\prime}$ above the melting layer. Once the airmass descends to the melting layer, melting of ice particles contained in the airmass decreases the airmass $\theta^{\prime}$, which leads to $\partial \theta^{\prime} / \partial z>0$ in the melting layer of the subsidence region. Consequently, ASADVPT has positive value there. It is consistent that the outside warming did not appear in the dynamically induced ASADVPT (Figs. 8m,n).

In contrast to the early stages of RI (ST-I and ST-II), there was large warming ( $>6 \mathrm{~K}$ for $6 \mathrm{~h}$ ) in almost all levels within the eye during the later stages of RI (Figs. 8c,d). The warming corresponds to a rapid amplification of the lower warm core in RI (Fig. 1b). Then the model-based ASADVPT was no longer dominate within the eye (Figs. 8k,1). Alternatively, the eye warming can be interpreted as significant axisymmetric subsidence in the eye (Figs. 8g,h). The significant subsidence drives strong baroclinicity and dynamical efficiency in the inner edge of the eyewall (K19). Therefore, the results indicate that the eye dynamical warming was dominate in the early periods of the storm RI (including before the RI onset). Consequently, the PV mixing can deepen the central pressure around the RI onset. Note that iteration procedures in the PV inversion (required in the omega equations) could not find convergent solutions because of relatively strong nonlinearity in the diagnosed equations during the later stages of RI. This limitation has been already pointed out by Wang and Zhang (2003). The strong nonlinearity is mainly caused by large asymmetric flows associated with locally active convection in the eyewall. It indicates continuous PV 
Actual change $(\partial \theta / \partial t)$ (a) ST-I

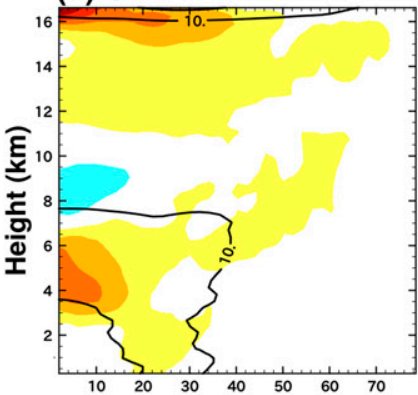

(b) ST-II

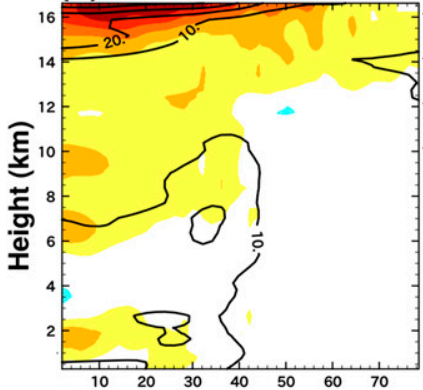

(c) ST-III $^{20}$
AXADVPT

(e) ST-I

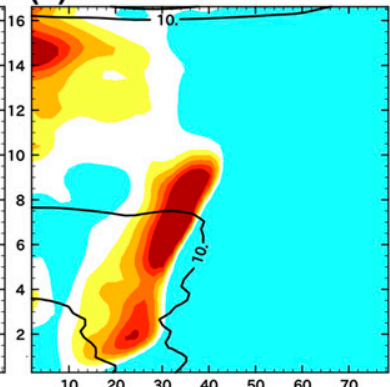

(f) $S T-I I$

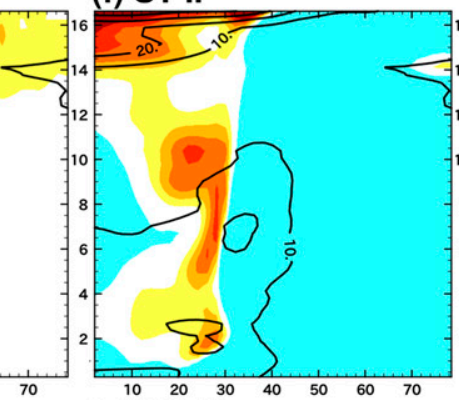

(g) ST-III

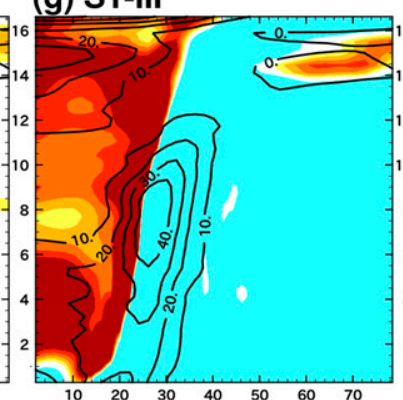

(h) ${ }^{10} \mathrm{ST}^{20}-\mathrm{IV}^{30}$

(d) ST-IV
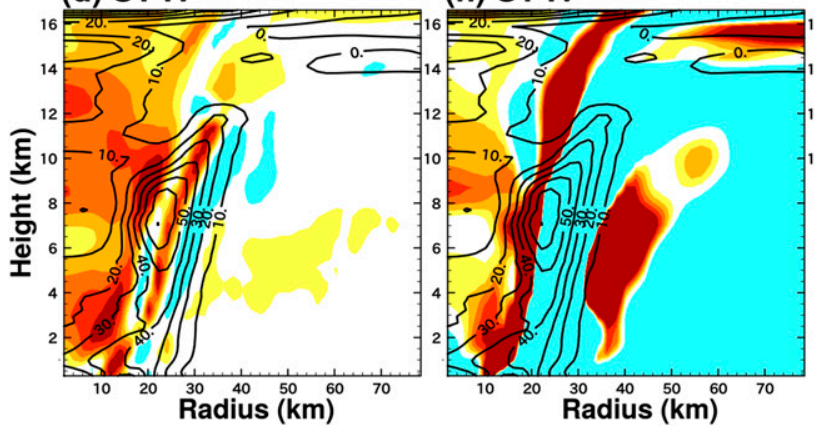

\section{(i) ST-I}

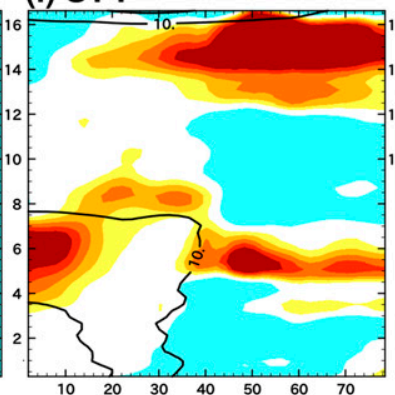

(j) ST-II
ASADVPT

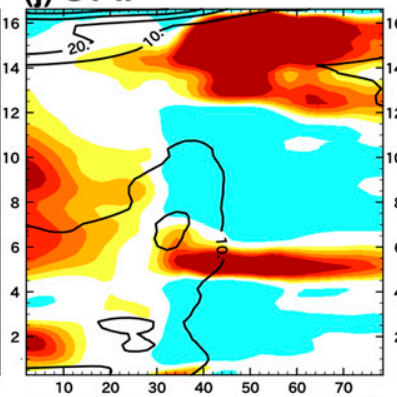

(k) ST-III

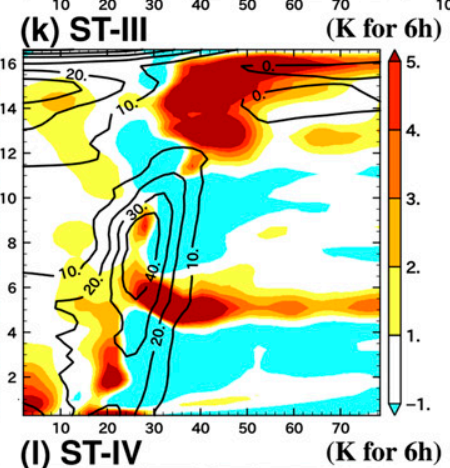

(I) ${ }^{10} \mathrm{ST}-\mathrm{IV}$
ASADVPT (OMEGA)

(m) ST-I (K for $6 h$ )

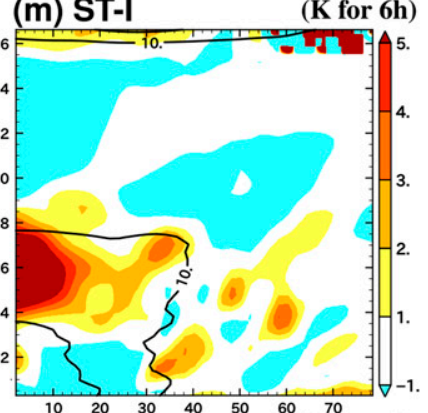

(n) $\mathrm{ST}^{20}-\mathrm{II}$

(K for 6h)

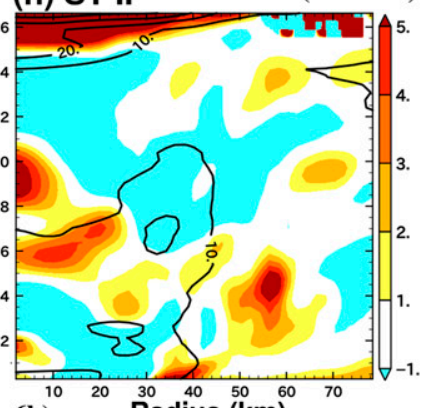

Radius (km)

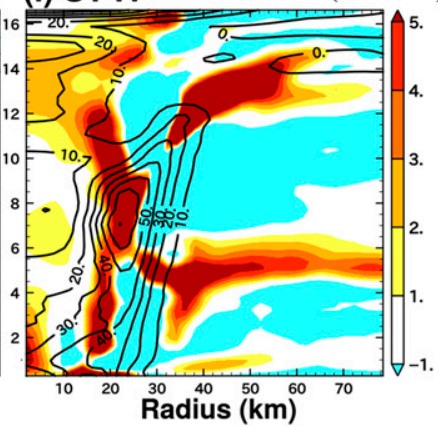

FIG. 8. Radius-height cross sections of (a)-(d) actual change of $\bar{\theta}$, (e)-(h) axisymmetric advection of $\bar{\theta}$, (i)-(l) asymmetric advection of $\bar{\theta}$ due to the model output, and (m)-(n) asymmetric advection of $\bar{\theta}$ due to the flows derived by the omega-equation diagnosis in Eqs. (4)-(6) without the diabatic heating and momentum forcing (colors; K) for $6 \mathrm{~h}$ during (a),(e),(i),(m) 1800 UTC 6 Nov-0000 UTC 7 Nov, (b),(f),(j),(n) 0000-0600 UTC 7 Nov, (c),(g),(k) 1200-1800 UTC 7 Nov, and (d),(h),(l) 1800 UTC 7 Nov-0000 UTC 8 Nov 2013. Contours denote azimuthally and temporally averaged PV (PVU) for each $6 \mathrm{~h}$. In the later stages of ST-III and ST-IV, iteration procedures in the PPVI (required in the omega equations) could not find convergent solutions because of relatively strong nonlinearity in the diagnosed equations. 
mixing associated with the asymmetric flows in the eyewall in the later stage as mentioned in comparison with observations.

\section{BL inflow and eye core convection}

\section{a. BL inflow and convective PV towers}

The PV budget and PPVI clarified that the pressure falling at the storm center was associated with radial redistribution of PV by the PV mixing at the RI onset. In axisymmetric views, the simulated storm had notable increases in the maxima of inflow and tangential wind, associated with gradual deepening of the central pressure around the RI onset (Fig. 9a). Thus, the pressure deepening was closely linked to the increase of axisymmetric inflow. For asymmetric views, characteristics of significantly strong convection are indicated by the 98th-percentile value $w_{98}$ of cumulative distribution of updraft within a radius of $100 \mathrm{~km}$ in the simulated storm (Fig. 9b). The 98th-percentile values in the tangential and vertical velocities are calculated after vertical average of each variable from the surface to a $1-\mathrm{km}$ height (corresponding to the $\mathrm{BL}$ ). Then sampling points of 7845 are exactly defined at model grid points included within the $100-\mathrm{km}$ radius. Coinciding with the increase of the 98th-percentile value $v_{98}$ of the tangential wind within the $\mathrm{BL}$ in the RI period, the $w_{98}\left(\sim 0.6 \mathrm{~m} \mathrm{~s}^{-1}\right)$ before the RI onset gradually increased up to $1 \mathrm{~m} \mathrm{~s}^{-1}$ by the end of the RI period. This value is much weaker than observations (e.g., Rogers et al. 2013b) due to relatively coarse horizontal resolution in the present simulation. We examine the sensitivity of the model grid spacing to amplitudes of the updraft and PV in section $4 \mathrm{~b}$.

The mean radius $R\left(w_{98}\right)$ of grid points with the top $2 \%$ of the cumulative distribution of updrafts is located in the outer side of the mean radius $R\left(v_{98}\right)$ of grids with the top $2 \%$ of the cumulative distribution of tangential wind before the RI onset. During the RI period, $R\left(w_{98}\right)$ was smaller than $R\left(v_{98}\right)$, except from 0100 to 0600 UTC 7 November 2013 (Fig. 9c). This indicates that strong convection was located inside the RMW, consistent with Rogers et al. (2013b). The inside location of the strong convection can induce eyewall contraction through inward advection of the absolute angular momentum (K19).

We consider the vertical PV flux (i.e., the product of vertical velocity and PV) as a parameter for tracking the collocation of strong updraft with high PV. The PV flux maximum indicates the convective PV tower. Before the $\mathrm{RI}$ onset, grids with the top $2 \%$ of the cumulative distribution of the PV flux $\left(\mathrm{PVF}_{98}\right)$ are broadly located along the RMW (Fig. 10a). Most grid points correspond

\section{(a) Azimuthal average}

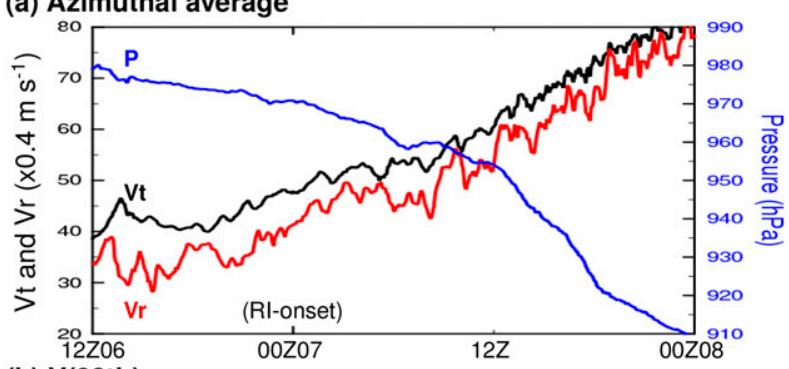

(b) $V(98$ th)

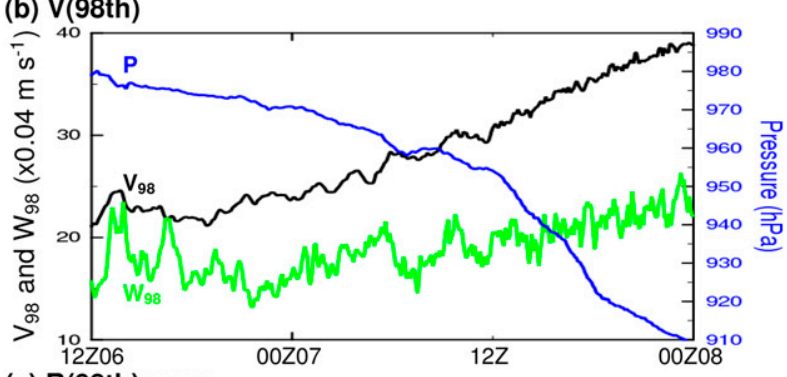

(c) R(98th)mean

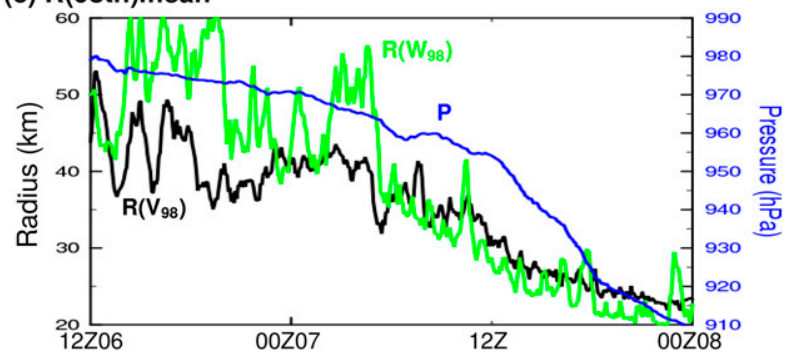

FIG. 9. Time series of (a) azimuthal averages of tangential velocity (black) and inflow (red), (b) the 98th-percentile values of tangential velocity (black) and vertical motion (green), and (c) averaged radii over grid points with a value greater than the 98th-percentile value for tangential velocity (black) and vertical motion (green). In all panels, the blue lines indicate the simulated central pressure. The 98th percentiles are estimated by the vertical averages from the surface to a height of $1 \mathrm{~km}$, which is for sampling 7845 grid points.

to grids with strong updrafts (Fig. 10i). $\mathrm{PVF}_{98}$ grid points are mostly located within the RMW at the RI onset (Fig. 10j). During the RI period, radial spread of the $\mathrm{PVF}_{98}$ points gradually became narrow and within the RMW (Figs. 10a-d). Coinciding with increase of BL inflow, the $\mathrm{PVF}_{98}$ points concentrated to radii with steep $\partial u / \partial r$ in an axisymmetric manner (Figs. 10e-h). This indicates that the $\mathrm{PVF}_{98}$ points can be linked to strong updrafts associated with shock-like structures in the BL inflow as proposed by Williams et al. (2013). Locations of the $\mathrm{PVF}_{98}$ correspond to locations with the steep change of the radial inflow even in the horizontal (asymmetric) view (Figs. 10i-1). In particular, although some strong updrafts $\left(>1.4 \mathrm{~m} \mathrm{~s}^{-1}\right)$ were present outside the RMW, these are points not included in the $\mathrm{PVF}_{98}$ (Figs. 10k,1). The points are not located near the steep 
(a) $18 Z 06$

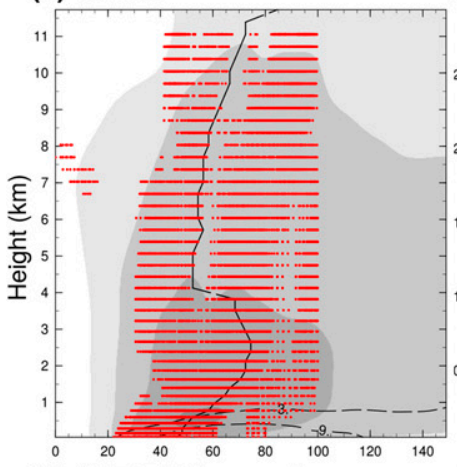

(b) $00 Z 07$ (RI-onset)

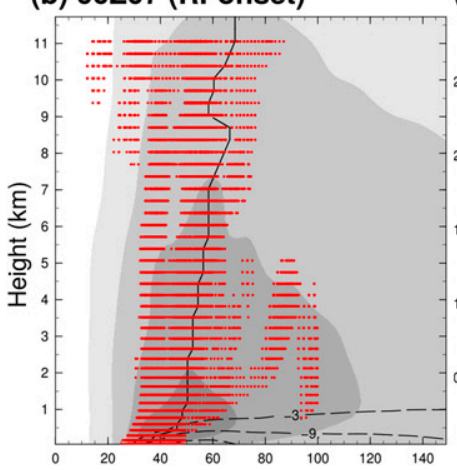

(c) $12 \mathrm{ZOT}$

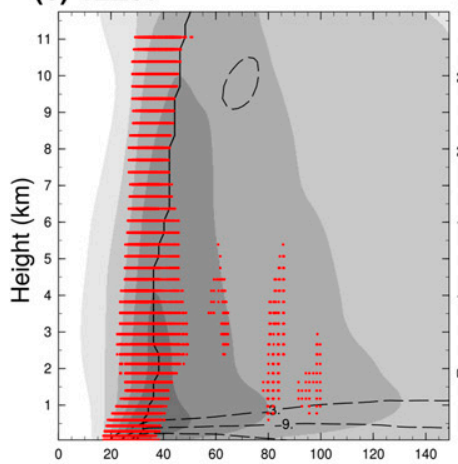

(d) $00 Z 08$

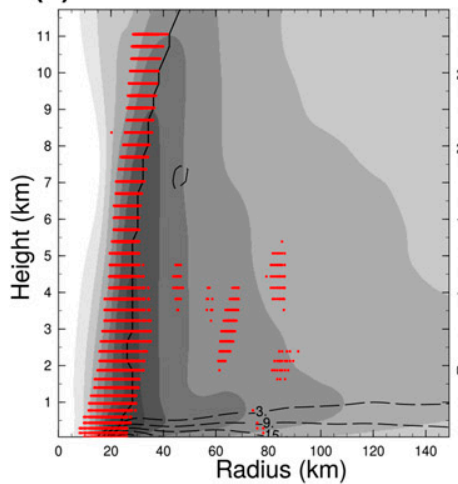

(e) $18 Z 06$

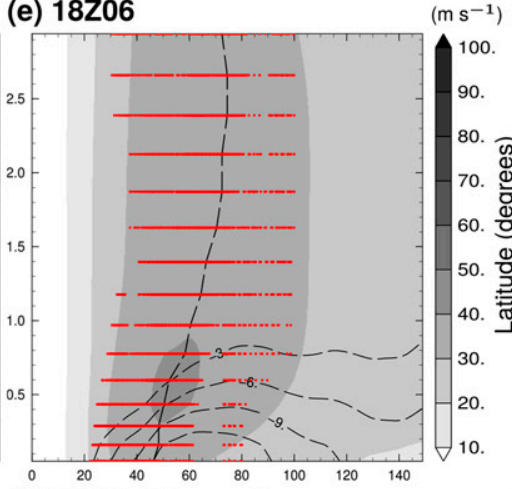

(f) $00 Z 07$ (RI-onset)

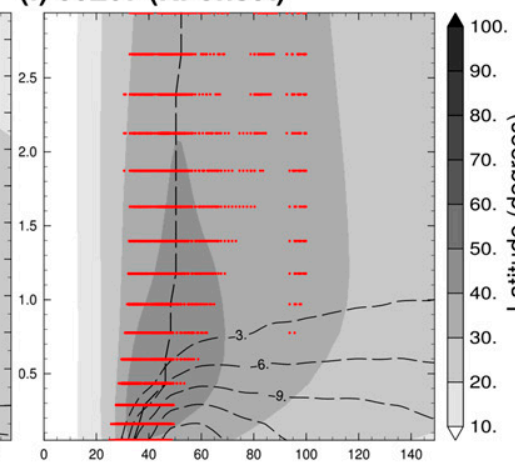

(g) $12 \mathrm{ZO} 7$

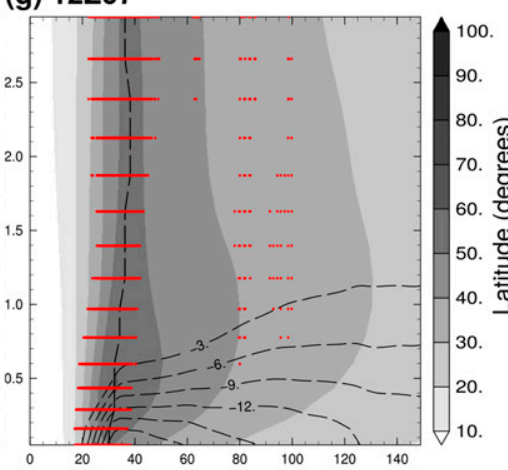

(h) $00 \mathrm{ZOB}$

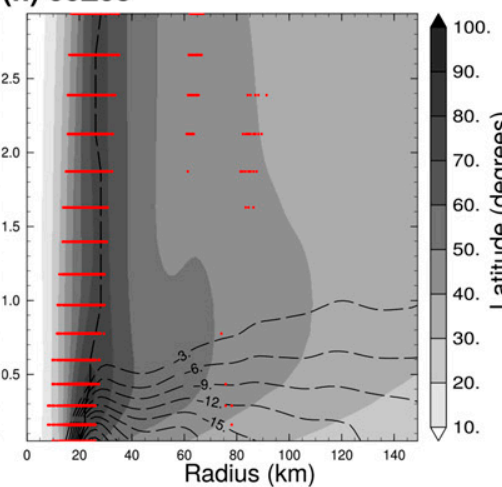

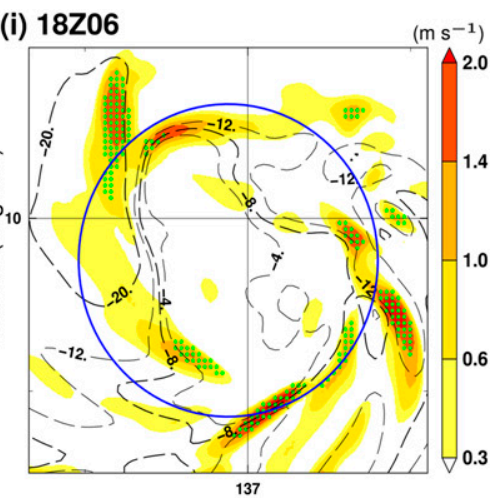

(j) $00 Z 07$ (RI-onset)

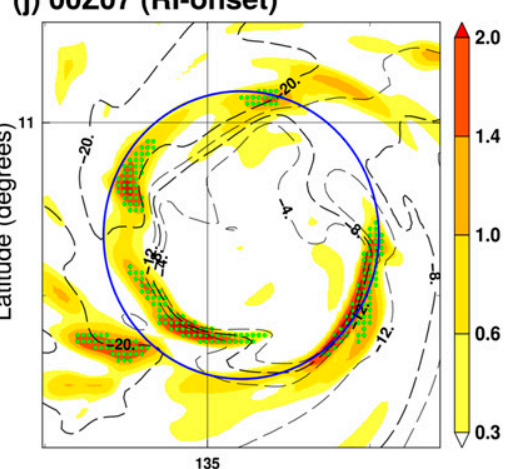

(k) $12 Z 07$

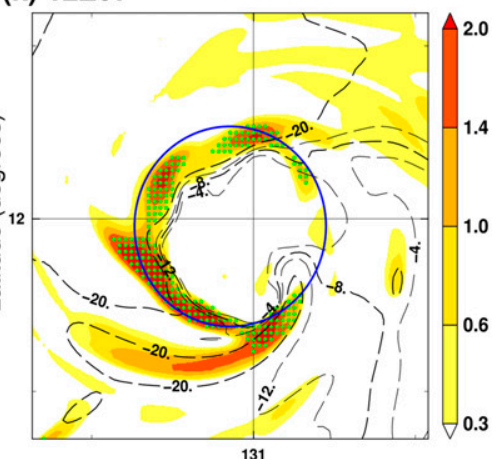

(I) $00 Z 08$

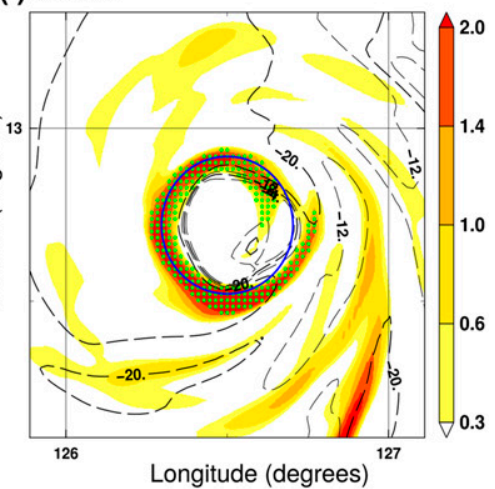

FIG. 10. (left),(center) Radius-height cross sections of the azimuthally averaged tangential wind (shaded; $\mathrm{m} \mathrm{s}^{-1}$ ) and radial inflow (dashed contours; $\mathrm{m} \mathrm{s}^{-1}$ ) and (right) horizontal distributions of vertical motion (colors; $\mathrm{m} \mathrm{s}^{-1}$ ) at a height of $1 \mathrm{~km}$ and radial inflow (dashed contours; $\mathrm{m} \mathrm{s}^{-1}$ ) at a height of $50 \mathrm{~m}$ at (top to bottom) 1800 UTC 6 Nov, 0000 UTC 7 Nov, 1200 UTC 7 Nov, and 0000 UTC 8 Nov 2013. The center panels zoom in on BL in the left panels. Red dots indicate radii of grids with the top $2 \%$ of the cumulative distribution of the vertical PV flux. Green dots denote horizontal projection of the red dots at the $1-\mathrm{km}$ height. Black dashed line denotes the RMW. Blue circle in the right panels indicates the RMW at the 1-km height. 
$\partial u / \partial r$ region. Finally, we note that the difference in the degree of spread of the $\mathrm{PVF}_{98}$ points in Figs. 10a-10d indicates the asymmetries of the convective PV tower. Near the mature stage, the narrowness of the composite $\mathrm{PVF}_{98}$ suggests the symmetry of the convective PV tower (Figs. 10d,1).

\section{b. Sensitivity of $P V$ values to model resolution}

The maximum of PV around the inner core was up to 100 PVU in the 2-km simulation of the CReSS model. Martinez et al. (2019) analyzed high-PV towers associated with about 250 PVU in the mature stage of Hurricane Patricia (2015). The relatively low PVs in the present study might be due to coarse horizontal resolution in our simulation. Sensitivity of the model resolution to the PV values is examined by the same configuration of the CReSS model, except for different horizontal resolutions of $1 \mathrm{~km}$ and $500 \mathrm{~m}$. The tests have smaller model domain (not shown) and a later initial time of 1800 UTC 7 November 2013 than the original $2-\mathrm{km}$ simulation to conserve computer resources.

The PV maximum in the $1-\mathrm{km}$ simulation is 150 PVU in the eyewall (Fig. 11b), and the maximum in the 500-m simulation is locally 200 PVU (Fig. 11c), which is in general agreement with the observation of Martinez et al. (2019). We highlight the high-PV values in our three-dimensional high-resolution simulation. According to our PV budget, high PV in the convective PV towers is supplied by eyewall convection. Thus, the large PV values can be linked to updrafts on the BL top. Our model deep convection initiated from the BL inside the RMW, with its vorticity amplified mainly by vortex-tube stretching and tilting processes, is in general agreement with the rotating convective paradigm (Montgomery and Smith 2017).

Updrafts at a $1.6-\mathrm{km}$ height exhibited maxima of $10 \mathrm{~m} \mathrm{~s}^{-1}$ in the $1-\mathrm{km}$ simulation, and $20 \mathrm{~m} \mathrm{~s}^{-1}$ in the $500-$ $\mathrm{m}$ simulation (Figs. 11e,f). Strong updrafts reaching about $20 \mathrm{~m} \mathrm{~s}^{-1}$ were seen in the BL even at a height of $434 \mathrm{~m}$ (Fig. 12c). The maxima in the 500-m simulation almost reached updraft magnitudes near the shock-like region similar to the aircraft observation in Hurricane Hugo (1989) as reported by Williams et al. (2013). For example, the radial wind had a change of $20 \mathrm{~m} \mathrm{~s}^{-1}$ in a span of $2 \mathrm{~km}$ around a radius of $20 \mathrm{~km}$ in the $500-\mathrm{m}$ simulation. The steep change of the radial wind cannot be represented in the 2- and $1-\mathrm{km}$ simulations due to relatively coarse resolution (Figs. 12a,b). Strong updrafts in these simulations were strongly connecting with high PV towers (Figs. 11g-i). In an asymmetric view, values of the updraft and PV also increased as the model resolution increased, and the strongest updraft in low levels of the 500-m simulation had the high PV value of about 200 PVU around the 20-km radius (Figs. 12d-f).

\section{c. Comparison with observations on the $(R, \theta)$ space}

Recently, Martinez et al. (2019) conducted detailed analyses of PV in Hurricane Patricia (2015) using highresolution aircraft observations on the angular momentum related potential radius $(R)$ and isentropic $(\theta)$ coordinates. The use of $R$ allows detail examination of the physical fields near the inner-core region (e.g., Hack and Schubert 1986). Martinez et al. (2019) found that 1) a PV maximum around the eyewall located radially inward of heating maximum in the eyewall, and 2) the PV maximum was along a certain $R$ surface during the RI and mature stages even in presence of significant RMW contraction.

Figure 13 shows the PV and diabatic heating distribution projected on an $R-\theta$ map at different times from the present simulation. In the early period of RI, the PV peak corresponding to the hollow tower was located around $R=200-280 \mathrm{~km}$ (Fig. 13b). The radial location of the PV peak is slightly different from location of the heating peak $(R \sim 300 \mathrm{~km})$ around the eyewall. This feature was also exhibited before the RI onset (Fig. 13a). Moreover, constant PV surfaces intersect with constant heating surfaces around the eyewall. In particular, constant surfaces of the heating are almost normal to the constant PV surfaces in layers from 320 to $330 \mathrm{~K}$ and from 340 to $350 \mathrm{~K}$ (Fig. 13b). According to Martinez et al. (2019), the intersections in the lower and upper layers indicate source and sink of PV due to the diabatic heating, respectively. The location of the PV maximum was almost same in the later period of RI, and always inward of the eyewall heating (Figs. 13c,d). The characteristics are in general agreement with the observation by Martinez et al. (2019). Martinez et al. (2019) further suggested that the feature of the inward location of the convective PV tower can be induced by eddy torques according to a PV-tendency equation on an $R-\theta$ map. The eddy torques are composed of surface friction, turbulent mixing, and asymmetric PV advection (i.e., the ASADV and FRIC terms in our PV budget). On the basis of our budget analysis in ST-II, the FRIC term is negative on the outer edge of the PV peak and positive in the inner side of the peak (Fig. 6g). Moreover, the ASADV term has briefly the same pattern but a much larger contribution than that of the FRIC term (Fig. 6e). Thus, our budget analysis indicates that the slightly different location of the convective PV tower is induced by eddy torques including the PV mixing, supporting their argument.

The PV budget analysis indicates the patterns of positive in the inner side of the PV peak and negative on the outer edge of the PV even in ST-III and ST-IV (not shown). Thus, our results indicate that the hollow tower 

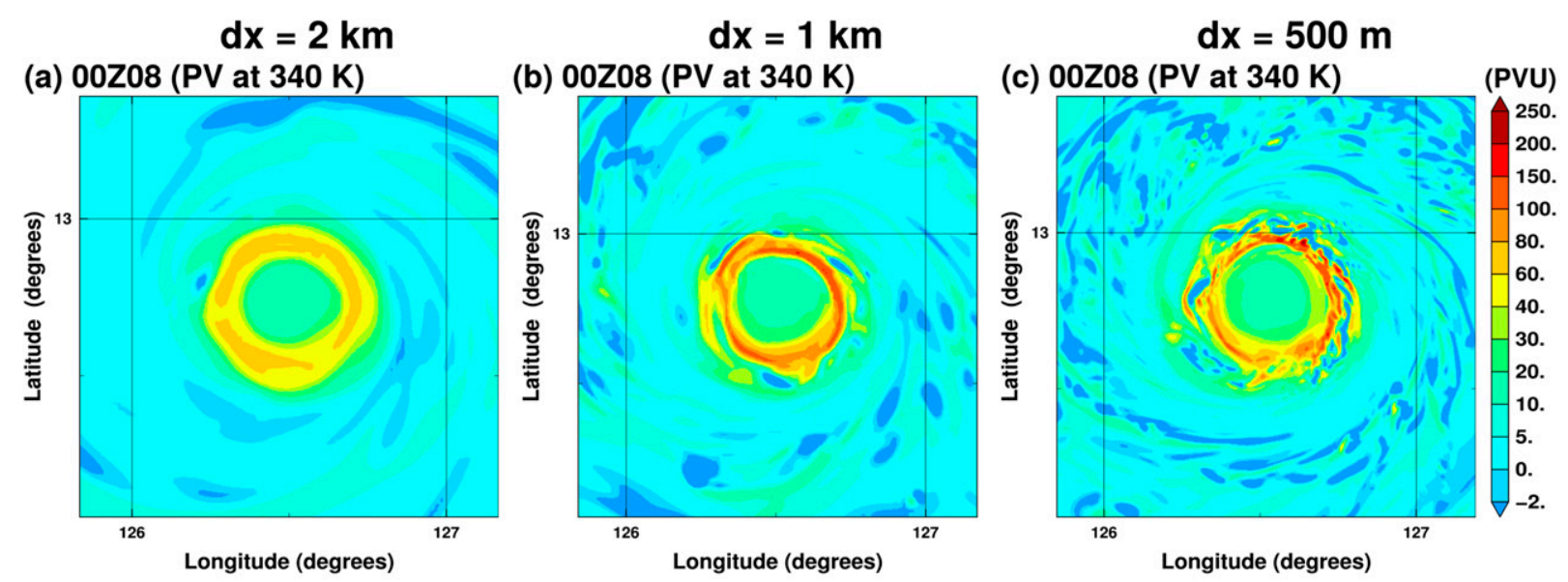

(d) $00 Z 08(\mathrm{~W}$ at $1.6 \mathrm{~km})$

(e) $00 \mathrm{Z08}(\mathrm{W}$ at $1.6 \mathrm{~km})$
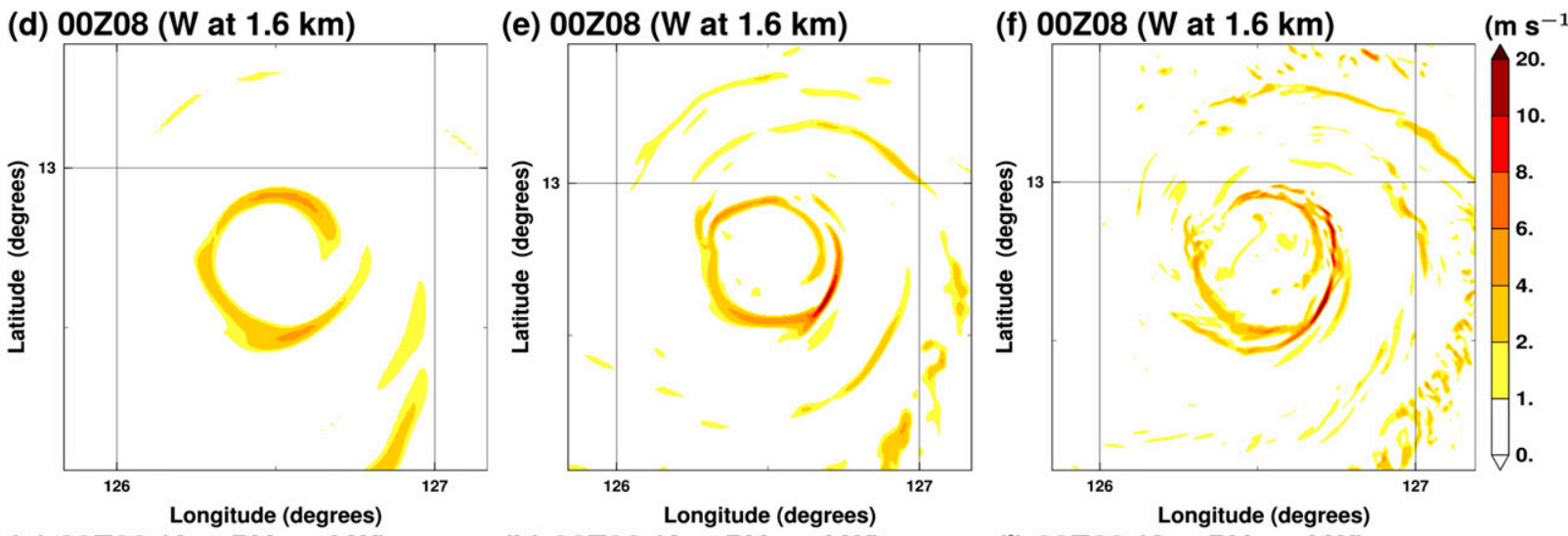

(g) $00 Z 08$ (Ax. PV and W)

(h) $00 Z 08$ (Ax. PV and W)
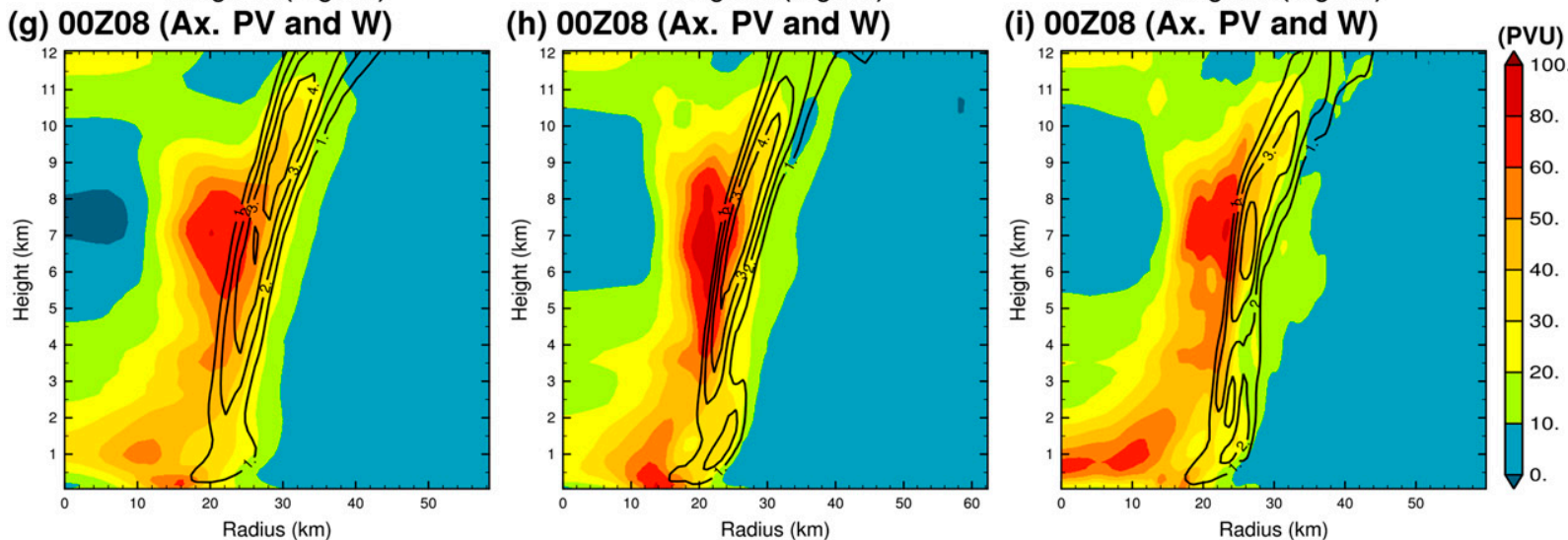

FIG. 11. Horizontal distributions of (a)-(c) PV on 340-K isentropic surface and (d)-(f) vertical velocity at 1.6-km height, and (g)-(i) radius-height cross section of azimuthally averaged PV (colors; PVU) and updraft (contours; $\mathrm{m} \mathrm{s}^{-1}$ ) at 0000 UTC 8 Nov 2013 . Simulation resolutions are (left) $2 \mathrm{~km}$, (center) $1 \mathrm{~km}$, and (right) $500 \mathrm{~m}$.

supplies high PV to the storm center via PV mixing during the RI and mature stages, in general agreement with the observation of Martinez et al. (2019).

\section{Summary and concluding remarks}

We have studied the RI dynamics with a $2-\mathrm{km}$ resolution full-physics cloud-resolving model simulation of Supertyphoon Haiyan (2013). The simulated storm underwent two periods of significant central pressure falls between 1800 UTC 6 November-1200 UTC 7 November (the initial stage of the RI) and 1200 UTC 7 November0000 UTC 8 November 2013 (the later stage of the RI). To better understand the RI process, we have performed PV and potential temperature $(\theta)$ budgets, PPVI, and omega-equation diagnosis. 
(a) $\mathrm{dx}=\mathbf{2 k m}$

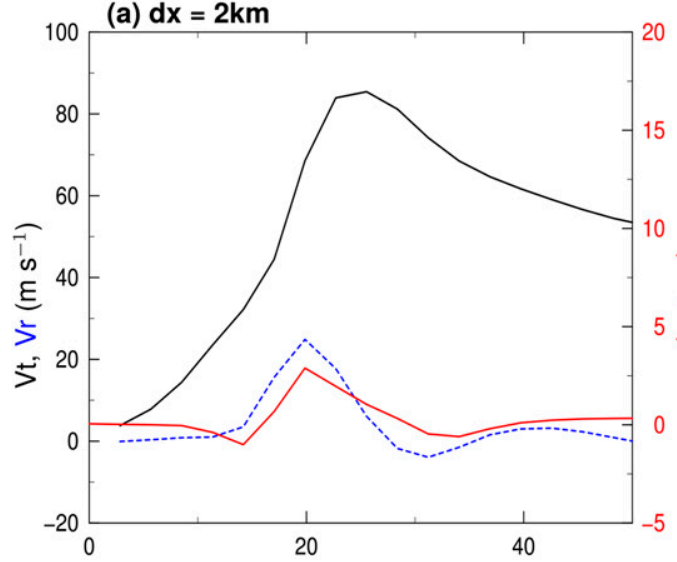

(b) $\mathrm{dx}=1 \mathrm{~km}$

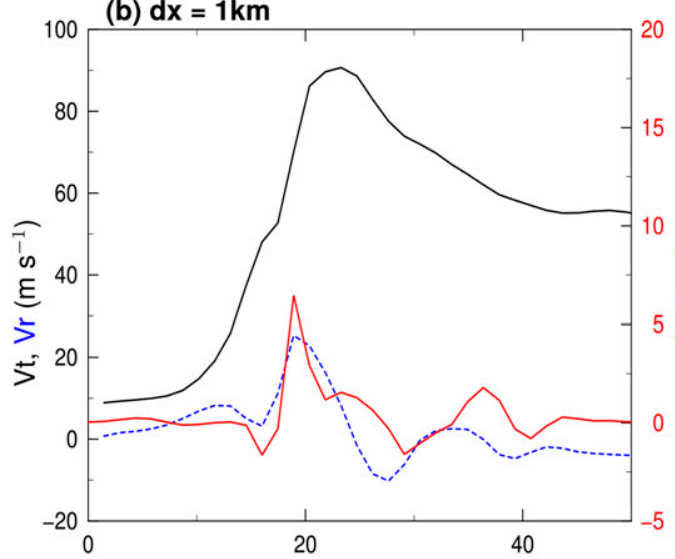

(c) $d x=500 m$

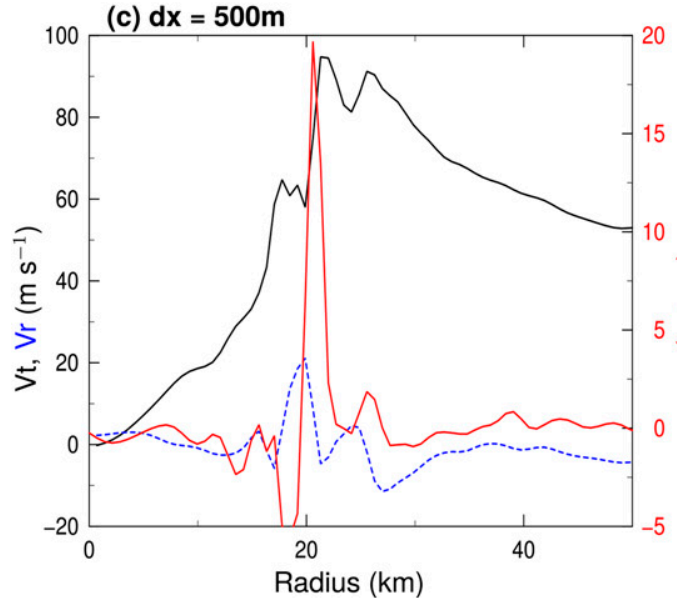

(d) $\mathrm{dx}=\mathbf{2 k m}$

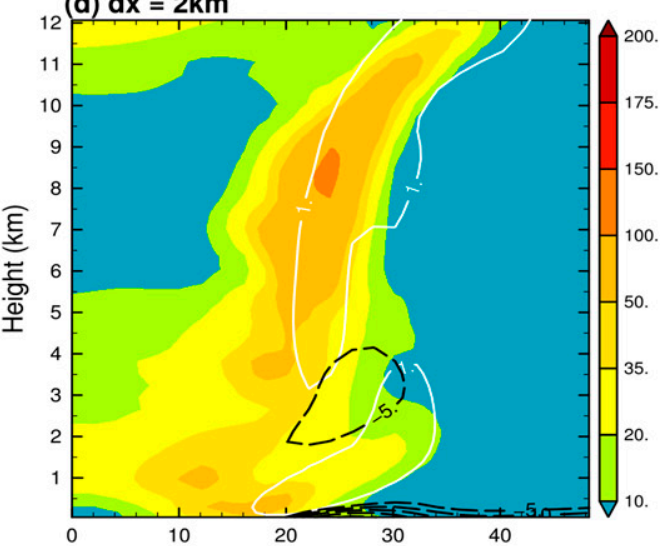

(e) $\mathrm{dx}=1 \mathrm{~km}$

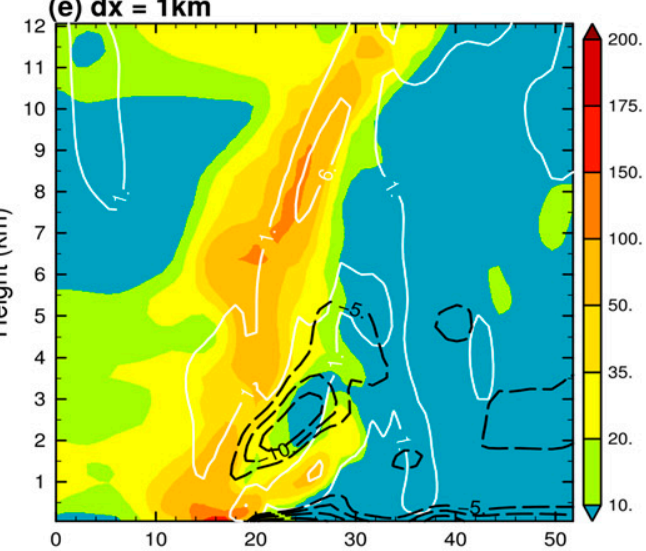

(f) $d x=500 m$

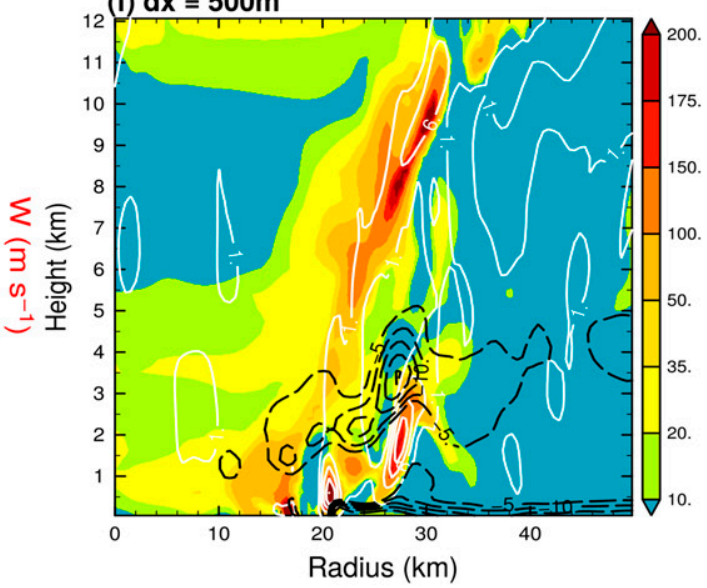

FIG. 12. Radial profiles of tangential wind (black), radial wind (dashed blue), and vertical motion (red) along the path with the maximum vertical velocity at a height of $434 \mathrm{~m}$ during ST-IV in (a) 2-km, (b) 1-km, and (c) 500-m simulations. Tangential and radial winds are measured as the ground-relative wind speed. (d)-(f) Radius-height cross sections of PV (colors; PVU), inflow (black dashed contours; $\mathrm{m} \mathrm{s}^{-1}$ ), and updraft (white solid contours; $\mathrm{m} \mathrm{s}^{-1}$ ) along the azimuthal angles in (a)-(c).

At the initial stage of the RI, the storm PV had an elliptical or polygonal eyewall structure and turned into a monopole near the storm center. The PV field increased around the $3-\mathrm{km}$ height for the $6-\mathrm{h}$ period before the RI onset and around $5 \mathrm{~km}$ for the 6 -h period after the RI onset. The increases were mainly contributed by the asymmetric PV advection corresponding to the PV mixing, consistent with Kossin and Schubert (2001). Our PPVI calculations indicate that the balanced response to the PV increase in the eye led to the 
(a) $21 Z 06$ (ST-I)

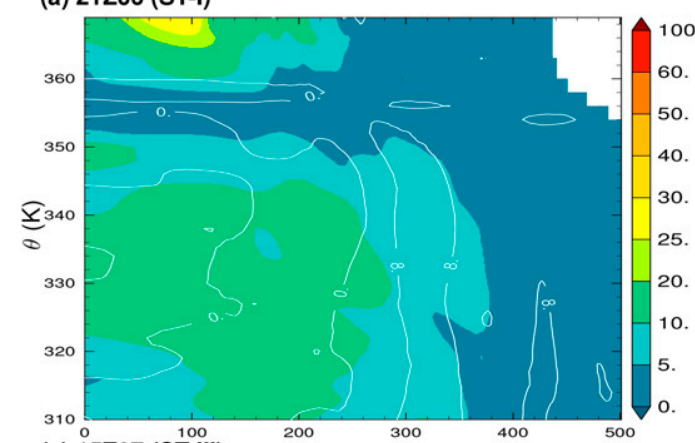

(c) $15 \mathrm{ZZ07}$ (ST-III)

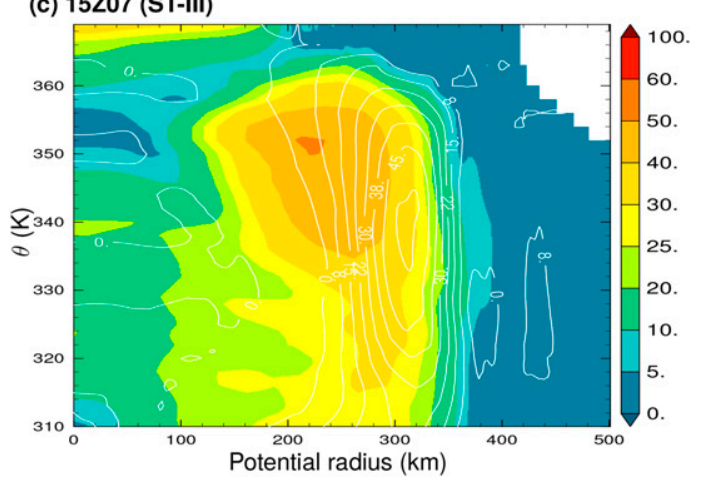

(b) $06 \mathrm{Z} 07$ (ST-II)

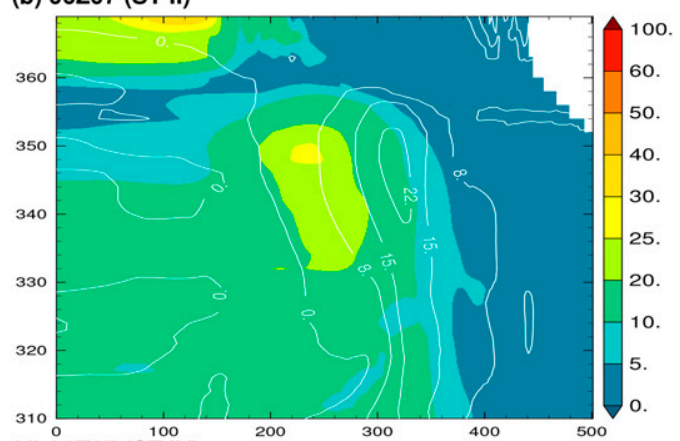

(d) $21 \mathrm{O} 207$ (ST-IV)

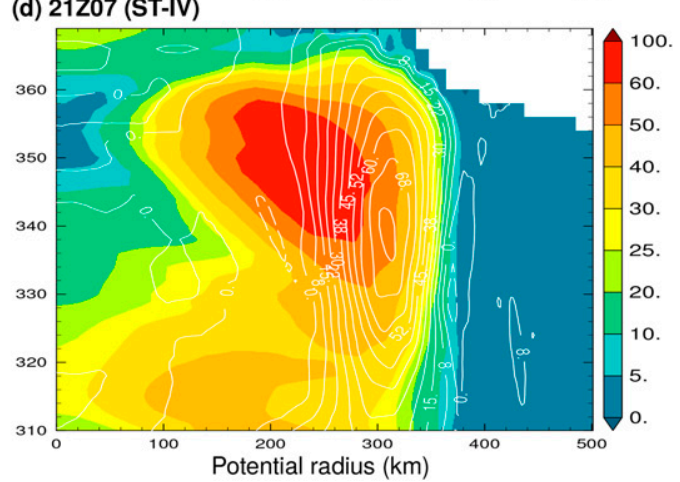

FIG. 13. Radius-height cross section of the PV (colors; PVU) and diabatic heating (contours; $\mathrm{Kh}^{-1}$ ) at (a) 2100 UTC 6 Nov (ST-I), (b) 0600 UTC 7 Nov (ST-II), (c) 1500 UTC 7 Nov (ST-III), and (d) 2100 UTC 7 Nov 2013 (ST-IV). Note that the abscissa is potential radius (km), as defined in Hack and Schubert (1986), and the ordinate is potential temperature $(\mathrm{K})$.

decrease in the inner-core pressure, which accounts for $60 \%-70 \%$ of the actual central pressure decrease. In particular, the PV mixing accounts for about $50 \%$ of the central pressure falls at this stage. The omega equation and $\theta$ budget diagnoses further show that the mid- and low-level eye around the RI onset is mostly warmed by the dynamically induced subsidence associated with the PV mixing. Our results suggest the importance of the asymmetric dynamics of PV mixing and the balanced response to the PV change in inner-core pressure decrease in the initial stage of the RI.

Coincident with the decreasing central pressure due to the PV mixing, increase in BL inflow leads to an increase of the tangential wind and a contraction of the RMW through enhancement of inward advection of angular momentum. The increase in the inflow can be closely linked to a nonlinear effect through the $u(\partial u / \partial r)$ term and a BL shock-like structure with strong eyewall updraft inside the RMW in the later stage of RI. In particular, an updraft magnitude of $20 \mathrm{~m} \mathrm{~s}^{-1}$ is simulated with the 500-m model resolution. Our simulation also indicates that the strongest $2 \%$ updraft is axisymmetric in the core region. The increase of PV field in the eyewall approximately $6 \mathrm{~h}$ after RI onset may be related to the BL flow. The increase of the PV field is due to the formation of the symmetric convective PV tower (Martinez et al. 2019). The convective PV tower is caused by vertical advection of the PV due to a strong updraft and PV generation by the convective diabatic heating in the eyewall. The eye is warmed by the strong subsidence associated with the symmetric convective PV towers in the later stage of RI.

Our interpretations of the convective PV tower may be supported by the observations of Hurricanes Hugo (1989) and Patricia (2015). Williams et al. (2013) reported that the aircraft observation in the Hugo's inner core exhibited a strong BL inflow $\left(\sim 20 \mathrm{~m} \mathrm{~s}^{-1}\right)$ and updrafts $\left(\sim 20 \mathrm{~m} \mathrm{~s}^{-1}\right.$ at the BL and $\sim 10 \mathrm{~m} \mathrm{~s}^{-1}$ at $\left.2682 \mathrm{~m}\right)$ coupled with large vorticities $\left(\sim 10^{-2} \mathrm{~s}^{-1}\right)$. This indicates the possible existence of the convective PV tower inside the RMW. The vorticity at $2682-\mathrm{m}$ height is broader in size than the region of the convective PV tower. If the Hugo observation is axisymmetric, it is in general agreement with the Hurricane Patricia radar observation (Fig. 10b of Martinez et al. 2019), that the strong updraft and diabatic heating region is located outside the high-PV region with some overlapping. The overlapping region is the region of convective PV tower. Our simulation at the mature stage of RI is in general agreement with the observation of Hurricane Patricia 


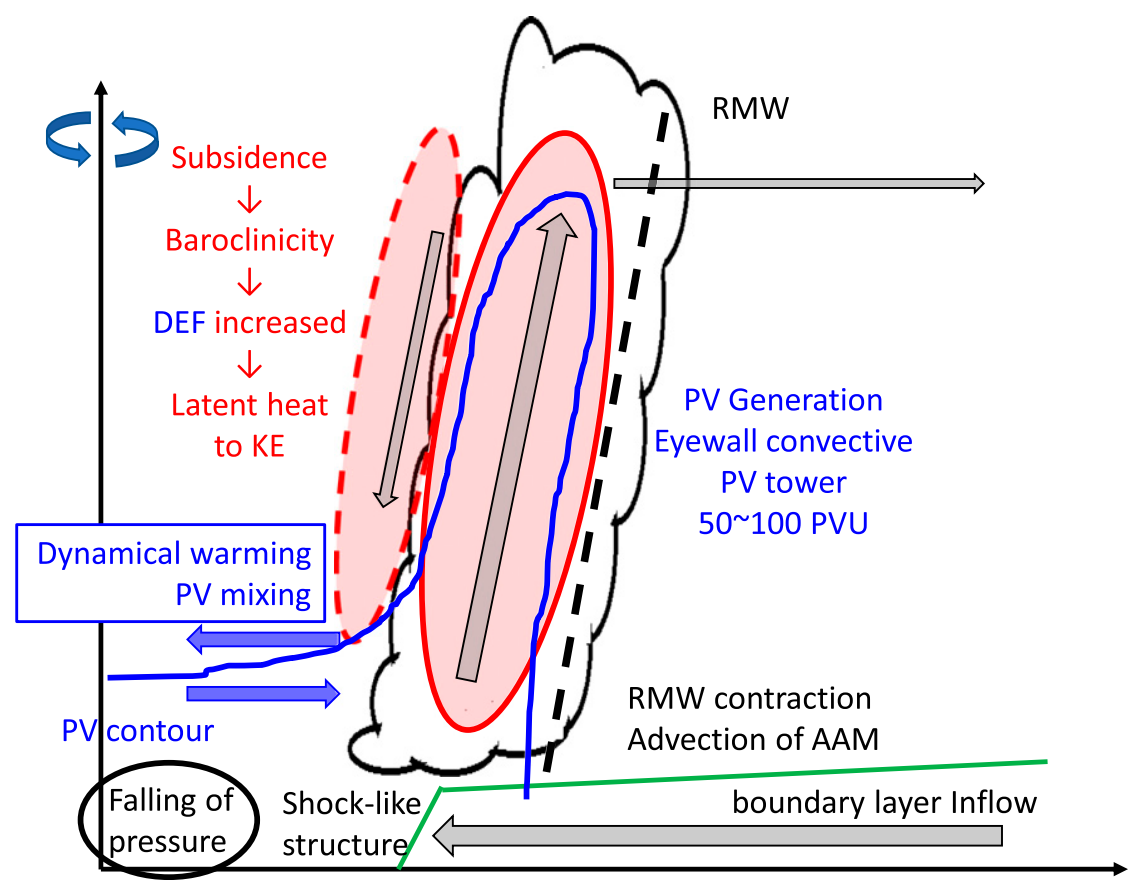

FIG. 14. A schematic illustration of the nonlinear feedback around the RI period, based on the model simulation and analysis in K19 and the present study. Thick gray arrows denote axisymmetric flows. The green line corresponds to the BL inflow region. The black dashed line indicates the approximate position of the RMW. The solid and dashed red elliptical regions show the regions of latent heat release and adiabatic warming, respectively. The black solid line denotes an outline of the eyewall cloud. See text for additional details.

(Martinez et al. 2019) in that the diabatic heating is located outside the high-PV region with some overlapping. Our simulation is in contrast to the symmetric model of Hausman et al. (2006) in that the diabatic heating in their model is mostly phase locked with the high-PV region without the radial separation. Our 500-m-resolution simulation produced a convective PV tower of 200 PVU, which is in general agreement with the observation of 250 PVU in Hurricane Patricia (Martinez et al. 2019). We focus on the sensitivity of the model resolution to values of PV and updraft in the present paper. The sensitivity of the cloud microphysics to the RI is a future research subject.

There were several PV mixing episodes occurred in low and midlevels before and after the RI onset in the simulation (Figs. 4 and 6). In the early stage of storm development, the Rossby radius of deformation in the storm is large and the Rossby height is small. The PV mixing may not induce significant pressure decrease (less mass response in the geostrophic adjustment). The pattern of pressure decrease is elongated horizontally with a smaller horizontal pressure gradient. When the storm reached a sufficient strength, the deformation radius becomes small and the Rossby height becomes deep (Kieu and Zhang 2010). The PV mixing then favors pressure decrease response. Moreover, the pattern of pressure decrease is elongated vertically with a larger horizontal pressure gradient. The large horizontal pressure gradient can enhance the BL radial inflow. The enhanced BL flow contributes to the formation of symmetric convective PV tower inside the RMW. The eye is warmed by the subsidence associated with the convective PV towers. The convective PV tower may also lead to another episode of PV mixing. All these dynamics are nonlinearly acting together to serve as indispensable building blocks of RI in the strong storms. Our results may help to explain the observation of Shu et al. (2012) that the RI often occurred in the strong storms.

In closing, we summarize nonlinearly collaborating dynamics in the simulated RI processes with the schematic shown in Fig. 14. Coincident with convective activation, a convective PV tower formed in the innercore region of the storm around the RI onset (the blue contour). High PV in the hollow tower is transported to the storm center through PV mixing (bold blue vectors). The enhanced PV, dynamical warming in the storm center, and its associated balanced response account for a half of a central pressure decrease. Associated with the central pressure decrease, axisymmetric BL inflow increases (bold gray vector within a region enclosed by green lines). The enhanced low-level inflow is linked to an increase of eyewall updraft (upward bold gray vector 
within eyewall cloud shaped by black curves). Associated with increases in the eyewall updraft and latent heating (a region bounded by the bold red ellipse), compensating subsidence results in adiabatic warming at the inner edge of the eyewall in the later stage of RI (Figs. 8g,h, and a region bounded by the dashed red ellipse in Fig. 14). The warming induces baroclinicity in the eyewall and increases the dynamic efficiency factor (DEF; K19) and make the kinetic energy generation by convective heating more efficient during RI. Increase of the Rossby height also favors development of the convective PV tower.

Acknowledgments. The authors thank Drs. W.H. Schubert and P. Ciesielski and three anonymous reviewers for their valuable and constructive comments. This study was supported by the Office of Naval Research Global under Grant N62909-15-1-2008, by the Ministry of Science and Technology (MOST) of Taiwan under Grants MOST-108-2119-M-002-022, MOST-107-2628M-002-016, MOST-106-2119-M-002-016, and MOST-1052111-M-003-003-MY3, and by the Ministry of Education, Culture, Sports, Science and Technology (MEXT) of Japan under JSPS Grant-in-Aid JP19H00705. The numerical experiments were performed using the Earth Simulator at the Japan Agency for Marine-Earth Science and Technology. This study used the Dennou-CommonLibrary (http://www.gfd-dennou.org/library/dcl/) for drawing and the STPK library (http://www.gfd-dennou.org/ library/davis/stpk/index.htm.en) for numerical analyses.

\section{APPENDIX}

\section{Estimation of the Central Pressure Decrease through Hydrostatic Balance}

We estimate contribution of each warm anomaly in the simulated double warm cores to the central pressure decrease based on hydrostatic balance (e.g., Zhang and Chen 2012). The hydrostatic balance represents a relationship between the surface pressure $p_{s}$ and columnaveraged air mass:

$$
p_{s}=p_{t}+g \int_{0}^{z_{t}} \rho d z
$$

where $\rho$ and $p_{t}$ denote air density and the pressure at the model top $\left(z=z_{t}\right)$, respectively. Evolution of $p_{s}$ from the start of the ST-I period (1400 UTC 6 November 2013), denoted as $\delta p_{s}$, can be expressed as follows:

$$
\delta p_{s}=p_{t}(t)-p_{t}(t=0)+\underbrace{g \int_{0}^{z_{t}}[\rho(z, t)-\rho(z, t=0)] d z}_{\text {WCC }} .
$$

Then the label as WCC indicates the contribution of the warm core to the pressure decrease, and is decomposed as follows:

$$
\mathrm{WCC}=\mathrm{LCC}+\mathrm{UCC},
$$

where

$$
\begin{gathered}
\mathrm{LCC}=g \int_{0}^{z_{m}}[\rho(z, t)-\rho(z, t=0)] d z, \\
\mathrm{UCC}=g \int_{z_{m}}^{z_{t}}[\rho(z, t)-\rho(z, t=0)] d z .
\end{gathered}
$$

LCC and UCC indicate contributions of warm anomaly in the lower and upper cores to the central pressure decrease, respectively, and $z_{m}$ is set at $11 \mathrm{~km}$.

\section{REFERENCES}

Chen, H., and D. Zhang, 2013: On the rapid intensification of Hurricane Wilma (2005). Part II: Convective bursts and the upper-level warm core. J. Atmos. Sci., 70, 146-162, https:// doi.org/10.1175/JAS-D-12-062.1.

Davis, C. A., and K. A. Emanuel, 1991: Potential vorticity diagnostics of cyclogenesis. Mon. Wea. Rev., 119, 1929-1953, https:// doi.org/10.1175/1520-0493(1991)119<1929:PVDOC>2.0.CO;2.

DeMaria, M., J. A. Knaff, and C. Sampson, 2007: Evaluation of longterm trends in tropical cyclone intensity forecasts. Meteor. Atmos. Phys., 97, 19-28, https://doi.org/10.1007/s00703-006-0241-4.

, C. R. Sampson, J. A. Knaff, and K. D. Musgrave, 2014: Is tropical cyclone intensity guidance improving? Bull. Amer. Meteor. Soc., 95, 387-398, https://doi.org/10.1175/BAMS-D-12-00240.1.

Hack, J. J., and W. H. Schubert, 1986: Nonlinear response of atmospheric vortices to heating by organized cumulus convection. J. Atmos. Sci., 43, 1559-1573, https://doi.org/10.1175/ 1520-0469(1986)043<1559:NROAVT>2.0.CO;2.

Halverson, J. B., J. Simpson, G. Heymsfield, H. Pierce, T. Hock, and L. Ritchie, 2006: Warm core structure of Hurricane Erin diagnosed from high altitude dropsondes during CAMEX-4. J. Atmos. Sci., 63, 309-324, https://doi.org/10.1175/JAS3596.1.

Harnos, D. S., and S. W. Nesbitt, 2016: Passive microwave quantification of tropical cyclone inner-core cloud populations relative to subsequent intensity change. Mon. Wea. Rev., 144, 4461-4482, https://doi.org/10.1175/MWR-D-15-0090.1.

Hausman, S. A., K. V. Ooyama, and W. H. Schubert, 2006: Potential vorticity structure of simulated hurricanes. J. Atmos. Sci., 63, 87-108, https://doi.org/10.1175/JAS3601.1.

Haynes, P. H., and M. E. McIntyre, 1990: On the conservation and impermeability theorems for potential vorticity. J. Atmos. Sci., 47, 2021-2031, https://doi.org/10.1175/15200469(1990)047<2021:OTCAIT>2.0.CO;2.

Hendricks, E. A., and W. H. Schubert, 2010: Adiabatic rearrangement of hollow PV towers. J. Adv. Model. Earth Syst., 2 (4), https://doi.org/10.3894/JAMES.2010.2.8.

$\longrightarrow,-$ R. K. Taft, H. Wang, and J. P. Kossin, 2009: Lifecycles of hurricane-like vorticity rings. J. Atmos. Sci., 66, 705-722, https://doi.org/10.1175/2008JAS2820.1.

- M. S. Peng, B. Fu, and T. Li, 2010: Quantifying environmental control on tropical cyclone intensity change. Mon. Wea. Rev., 138, 3243-3271, https://doi.org/10.1175/2010MWR3185.1. 
Ito, K., 2016: Errors in tropical cyclone intensity forecast by RSMC Tokyo and statistical correction using environmental parameters. SOLA, 12, 247-252, https://doi.org/10.2151/ SOLA.2016-049.

Kaplan, J., and M. DeMaria, 2003: Large-scale characteristics of rapidly intensifying tropical cyclones in the North Atlantic basin. Wea. Forecasting, 18, 1093-1108, https://doi.org/10.1175/ 1520-0434(2003)018<1093:LCORIT>2.0.CO;2.

Kieu, C. Q., and D.-L. Zhang, 2010: A piecewise potential vorticity inversion algorithm and its application to hurricane inner-core anomalies. J. Atmos. Sci., 67, 2616-2631, https://doi.org/ 10.1175/2010JAS3421.1.

— - V. Tallapragada, D.-L. Zhang, and Z. Moon, 2016: On the development of double warm-core structures in intense tropical cyclones. J. Atmos. Sci., 73, 4487-4506, https://doi.org/ 10.1175/JAS-D-16-0015.1.

Kossin, J. P., and W. H. Schubert, 2001: Mesovortices, polygonal flow patterns, and rapid pressure falls in hurricane-like vortices. J. Atmos. Sci., 58, 2196-2209, https://doi.org/10.1175/15200469(2001)058<2196:MPFPAR > 2.0.CO;2.

Kuo, H.-C., S. Tsujino, C.-C. Huang, C.-C. Wang, and K. Tsuboki, 2019: Diagnosis of the dynamic efficiency of latent heat release and the rapid intensification of Supertyphoon Haiyan (2013). Mon. Wea. Rev., 147, 1127-1147, https://doi.org/ 10.1175/MWR-D-18-0149.1.

Martinez, J., M. M. Bell, R. F. Rogers, and J. D. Doyle, 2019: Axisymmetric potential vorticity evolution of Hurricane Patricia (2015). J. Atmos. Sci., 76, 2043-2063, https://doi.org/10.1175/JASD-18-0373.1.

Miyamoto, Y., and T. Takemi, 2013: A transition mechanism for the spontaneous axisymmetric intensification of tropical cyclones. J. Atmos. Sci., 70, 112-129, https://doi.org/10.1175/ JAS-D-11-0285.1.

Montgomery, M. T., and R. K. Smith, 2017: Recent developments in the fluid dynamics of tropical cyclones. Annu. Rev. Fluid Mech., 49, 541-574, https://doi.org/10.1146/annurev-fluid-010816-060022.

Ohno, T., and M. Satoh, 2015: On the warm core of a tropical cyclone formed near the tropopause. J. Atmos. Sci., 72, 551-571, https://doi.org/10.1175/JAS-D-14-0078.1.

Rogers, R., and Coauthors, 2013a: NOAA's hurricane intensity forecasting experiment: A progress report. Bull. Amer. Meteor. Soc., 94, 859-882, https://doi.org/10.1175/BAMS-D-12-00089.1.

, P. Reasor, and S. Lorsolo, 2013b: Airborne Doppler observations of the inner-core structural differences between intensifying and steady-state tropical cyclones. Mon. Wea. Rev., 141, 29702991, https://doi.org/10.1175/MWR-D-12-00357.1.

—, J. A. Zhang, J. Zawislak, H. Jiang, G. R. Alvey III, E. J. Zipser, and S. N. Stevenson, 2016: Observations of the structure and evolution of Hurricane Edouard (2014) during intensity change. Part II: Kinematic structure and the distribution of deep convection. Mon. Wea. Rev., 144, 33553376, https://doi.org/10.1175/MWR-D-16-0017.1.

Schubert, W. H., and J. J. Hack, 1982: Inertial stability and tropical cyclone development. J. Atmos. Sci., 39, 1687-1697, https://doi.org/10.1175/1520-0469(1982)039<1687:ISATCD > 2.0.CO;2.

— , and B. D. McNoldy, 2010: Application of the concepts of Rossby length and Rossby depth to tropical cyclone dynamics. J. Adv. Model. Earth Syst., 2 (3), https://doi.org/10.3894/ JAMES.2010.2.7.

—, M. T. Montgomery, R. K. Taft, T. A. Guinn, S. R. Fulton, J. P. Kossin, and J. P. Edwards, 1999: Polygonal eyewalls, asymmetric eye contraction, and potential vorticity mixing in hurricanes.
J. Atmos. Sci., 56, 1197-1223, https://doi.org/10.1175/15200469(1999)056<1197:PEAECA > 2.0.CO;2.

_ S. A. Hausman, M. Garcia, K. V. Ooyama, and H.-C. Kuo, 2001: Potential vorticity in a moist atmosphere. J. Atmos. Sci., 58, 3148-3157, https://doi.org/10.1175/1520-0469(2001) $058<3148$ :PVIAMA $>2.0$. CO 2 .

Shu, S., J. Ming, and P. Chi, 2012: Large-scale characteristics and probability of rapidly intensifying tropical cyclones in the western North Pacific basin. Wea. Forecasting, 27, 411-423, https://doi.org/10.1175/WAF-D-11-00042.1.

Smith, R. K., and M. T. Montgomery, 2016: The efficiency of diabatic heating and tropical cyclone intensification. Quart. J. Roy. Meteor. Soc., 142, 2081-2086, https://doi.org/10.1002/qj.2804.

,-- , and V. S. Nguyen, 2009: Tropical cyclone spin-up revisited. Quart. J. Roy. Meteor. Soc., 135, 1321-1335, https:// doi.org/10.1002/qj.428.

Tao, C., and H. Jiang, 2015: Distributions of shallow to very deep precipitation-convection in rapidly intensifying tropical cyclones. J. Climate, 28, 8791-8824, https://doi.org/10.1175/JCLID-14-00448.1.

Tsuboki, K., and A. Sakakibara, 2002: Large-scale parallel computing of cloud resolving storm simulator. High Performance Computing, H. P. Zima et al., Eds., Springer, 243-259.

Tsujino, S., K. Tsuboki, and H.-C. Kuo, 2017: Structure and maintenance mechanism of long-lived concentric eyewalls associated with simulated Typhoon Bolaven (2012). J. Atmos. Sci., 74, 3609-3634, https://doi.org/10.1175/JAS-D-16-0236.1.

Vigh, J. L., and W. H. Schubert, 2009: Rapid development of the tropical cyclone warm core. J. Atmos. Sci., 66, 3335-3350, https://doi.org/10.1175/2009JAS3092.1.

Wang, X., and D.-L. Zhang, 2003: Potential vorticity diagnosis of a simulated hurricane. Part I: Formation and quasi balanced flow. J. Atmos. Sci., 60, 1593-1607, https://doi.org/10.1175/ 2999.1.

Williams, G. J., R. K. Taft, B. D. McNoldy, and W. H. Schubert, 2013: Shock-like structures in the tropical cyclone boundary layer. J. Adv. Model. Earth Syst., 5, 338-353, https://doi.org/ 10.1002/jame.20028.

Willoughby, H. E., 1998: Tropical cyclone eye thermodynamics. Mon. Wea. Rev., 126, 3053-3067, https://doi.org/10.1175/15200493(1998)126<3053:TCET>2.0.CO;2.

Yamada, H., and Coauthors, 2018: Double warm-core structure of Typhoon Lan (2017) as observed through upper-tropospheric aircraft reconnaissance during T-PARCII. 33rd Conf. on Hurricanes and Tropical Meteorology, Ponte Vedra, FL, Amer. Meteor. Soc., 8C.2, https://ams.confex.com/ams/33HURRICANE/ webprogram/Manuscript/Paper339931/201804_HurricaneConf_ Yamada_extendAbst.pdf.

Yau, M. K., Y. Liu, D. Zhang, and Y. Chen, 2004: A multiscale numerical study of Hurricane Andrew (1992). Part VI: Small-scale inner-core structures and wind streaks. Mon. Wea. Rev., 132, 1410-1433, https://doi.org/10.1175/15200493(2004)132<1410:AMNSOH > 2.0.CO;2.

Zawislak, J., H. Jiang, G. R. Alvey III, E. J. Zipser, R. F. Rogers, J. A. Zhang, and S. N. Stevenson, 2016: Observations of the structure and evolution of Hurricane Edouard (2014) during intensity change. Part I: Relationship between the thermodynamic structure and precipitation. Mon. Wea. Rev., 144, 3333-3354, https://doi.org/10.1175/MWR-D-16-0018.1.

Zhang, D.-L., and H. Chen, 2012: Importance of the upper-level warm core in the rapid intensification of a tropical cyclone. Geophys. Res. Lett., 39, L02806, https://doi.org/10.1029/ 2011 GL050578. 